\title{
B-RAF kinase drives developmental axon growth and promotes axon regeneration in the injured mature CNS
}

\section{Citation}

O'Donovan, K. J., K. Ma, H. Guo, C. Wang, F. Sun, S. B. Han, H. Kim, et al. 2014. "B-RAF kinase drives developmental axon growth and promotes axon regeneration in the injured mature CNS." The Journal of Experimental Medicine 211 (5): 801-814. doi:10.1084/jem.20131780. http:// dx.doi.org/10.1084/jem.20131780.

\section{Published Version}

doi:10.1084/jem.20131780

\section{Permanent link}

http://nrs.harvard.edu/urn-3:HUL.InstRepos:13454857

\section{Terms of Use}

This article was downloaded from Harvard University's DASH repository, and is made available under the terms and conditions applicable to Other Posted Material, as set forth at http:// nrs.harvard.edu/urn-3:HUL.InstRepos:dash.current.terms-of-use\#LAA

\section{Share Your Story}

The Harvard community has made this article openly available.

Please share how this access benefits you. Submit a story.

Accessibility 


\title{
B-RAF kinase drives developmental axon growth and promotes axon regeneration in the injured mature CNS
}

\author{
Kevin J. O’Donovan, ${ }^{1,2}$ Kaijie Ma, ${ }^{1,2}$ Hengchang Guo, ${ }^{1}$ Chen Wang, ${ }^{3,4}$ \\ Fang Sun, ${ }^{3,4}$ Seung Baek Han, ${ }^{5,6}$ Hyukmin Kim, ${ }^{5,6}$ Jamie K. Wong, ${ }^{7}$ \\ Jean Charron, ${ }^{9}$ Hongyan Zou, ${ }^{7,8}$ Young-Jin Son, ${ }^{5,6}$ Zhigang He, ${ }^{3,4}$ \\ and Jian Zhong ${ }^{1,2}$
}

\author{
'Burke Medical Research Institute, Weill Cornell Medical College of Cornell University, White Plains, NY 10605 \\ ${ }^{2}$ Brain and Mind Research Institute, Weill Cornell Medical College of Cornell University, New York, NY 10065 \\ 3F.M. Kirby Neurobiology Center, Boston Children's Hospital; and 'Department of Neurology; Harvard Medical School, Boston, MA 02115 \\ ${ }^{5}$ Shriners Hospitals Pediatric Research Center and ${ }^{6}$ Department of Anatomy and Cell Biology, Temple University \\ School of Medicine, Philadelphia, PA 19140 \\ ${ }^{7}$ Fishberg Department of Neuroscience and ${ }^{8}$ Department of Neurosurgery, Friedman Brain Institute, Icahn School of Medicine \\ at Mount Sinai, New York, NY 10029 \\ ${ }^{9}$ Centre de Recherche en Cancérologie de l'Université Laval, Centre Hospitalier Universitaire de Québec, Québec, \\ Québec G1R 2J6, Canada
}

\begin{abstract}
Activation of intrinsic growth programs that promote developmental axon growth may also facilitate axon regeneration in injured adult neurons. Here, we demonstrate that conditional activation of B-RAF kinase alone in mouse embryonic neurons is sufficient to drive the growth of long-range peripheral sensory axon projections in vivo in the absence of upstream neurotrophin signaling. We further show that activated B-RAF signaling enables robust regenerative growth of sensory axons into the spinal cord after a dorsal root crush as well as substantial axon regrowth in the crush-lesioned optic nerve. Finally, the combination of B-RAF gain-of-function and PTEN loss-of-function promotes optic nerve axon extension beyond what would be predicted for a simple additive effect. We conclude that cell-intrinsic RAF signaling is a crucial pathway promoting developmental and regenerative axon growth in the peripheral and central nervous systems.
\end{abstract}

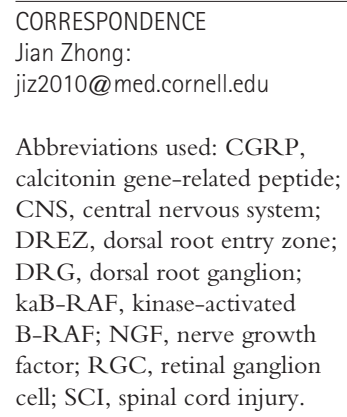

Abbreviations used: CGRP, calcitonin gene-related peptide; CNS, central nervous system; DREZ, dorsal root entry zone; DRG, dorsal root ganglion; kaB-RAF, kinase-activated B-RAF; NGF, nerve growth factor; RGC, retinal ganglion cell; SCI, spinal cord injury.

Axon growth is essential for the establishment of a functional nervous system as well as for the restoration of neuronal connectivity after injury or disease. It has long been hypothesized that reactivation of developmental growth mechanisms might help to achieve axon regeneration in the injured adult nervous system (Filbin, 2006). The role of MAP kinases in axon growth signaling has been much studied and discussed (Markus et al., 2002; Hanz and Fainzilber, 2006; Agthong et al., 2009; Hollis et al., 2009). However, depending on the model systems used, the outcomes have been controversial or even contradictory (Pernet et al., 2005; Sapieha et al., 2006; Hollis et al., 2009). We have shown that RAF-MEK signaling robustly promotes axon growth in primary sensory neurons in vitro (Markus et al., 2002). In vivo, conditional gene targeting studies

$\overline{\text { K.J. O’Donovan and K. Ma contributed equally to this paper. }}$ have shown that RAF signaling is necessary for developing sensory neurons to arborize in their target fields in the skin (Zhong et al., 2007). However, it remains unknown whether RAF signaling is sufficient to enable axon growth in vivo or whether concomitant activation of other signaling pathways is necessary to drive longrange axon projections. Furthermore, it is unclear whether this pathway can promote axon growth in neuronal populations beyond the sensory neurons and the extent to which it can be harnessed to promote regeneration in the injured central nervous system (CNS). To address these questions, we have used conditional B-RAF gain-of-function mouse models to show that

( 2014 O'Donovan et al. This article is distributed under the terms of an AttributionNoncommercial-Share Alike-No Mirror Sites license for the first six months after Noncommercial-Share Alike-No Mirror Sites license for the first six months after
the publication date (see http://www.rupress.org/terms). After six months it is available under a Creative Commons License (Attribution-Noncommercial-Share Alike 3.0 Unported license, as described at http://creativecommons.org/licenses/ by-nc-sa/3.0/). 
A

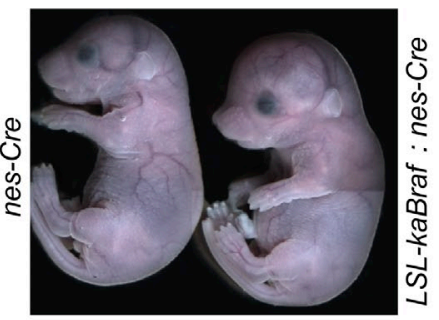

B

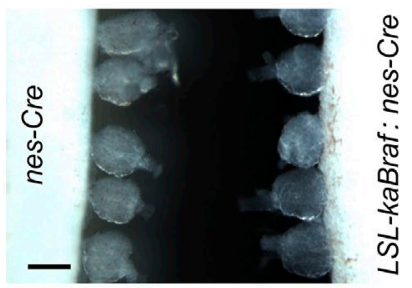

C
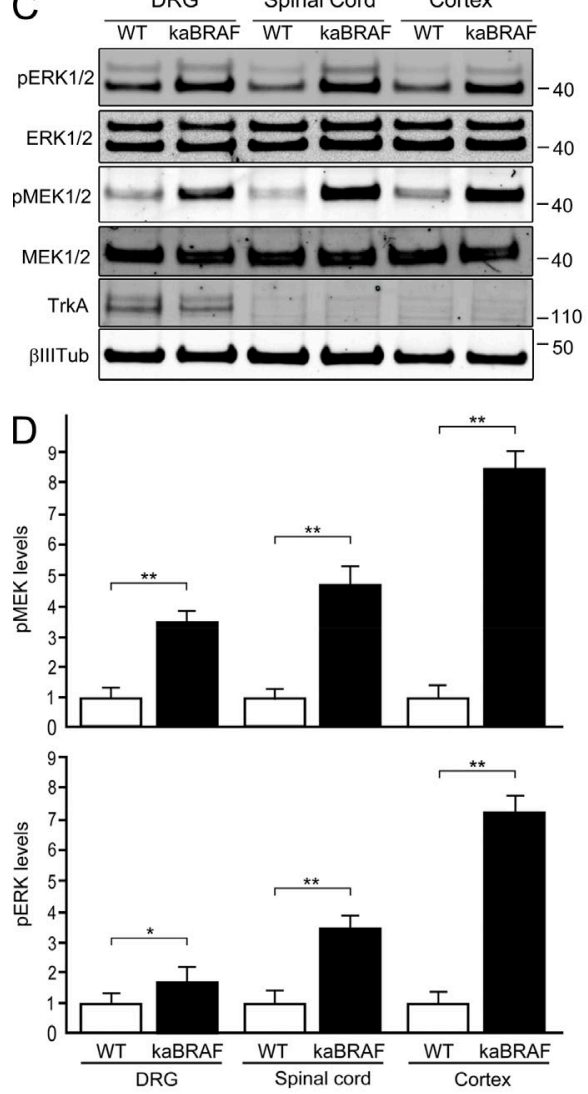

E

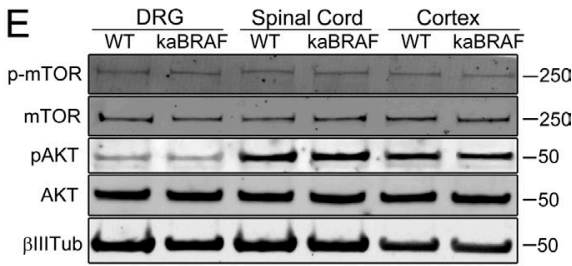

$\mathrm{F}$ DRG
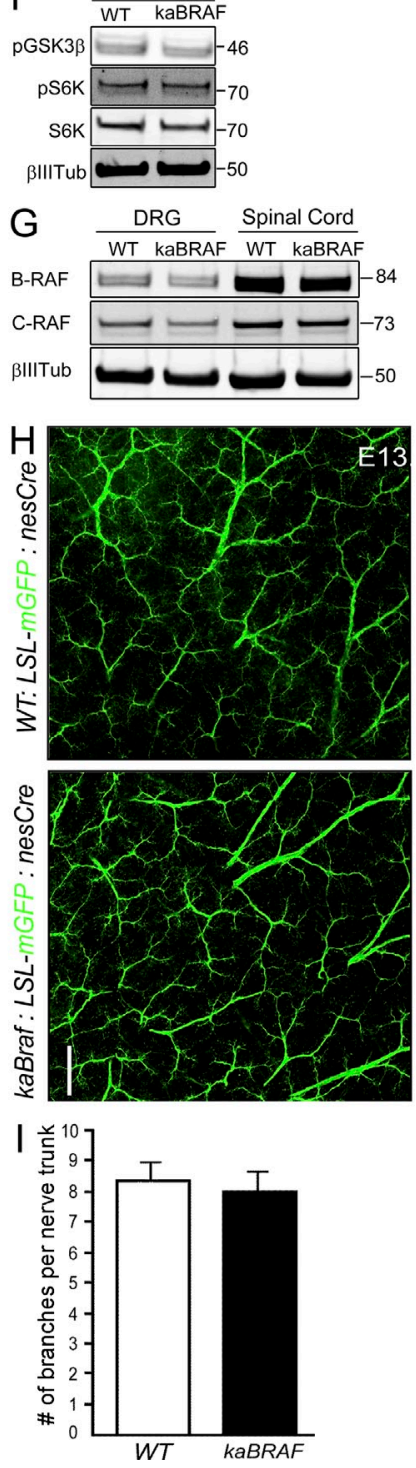

Figure 1. Conditional expression of kaBRAF specifically activates MAP kinase signaling in the nervous system. (A) E18.5 mouse embryos expressing kaB-RAF develop grossly normally, except for substantial hydrocephalus. (B) DRG size is unaffected by kaB-RAF expression. (C) Representative Western blots show increased levels of pMEK $1 / 2$ and pERK $1 / 2$ in the E12.5 neocortex and spinal cord. (D) Quantitation of Western blots as in $\mathrm{C}$. Amounts are normalized to corresponding $\beta$ III-tubulin levels. $n=4$ repeats with three animals per group for each bar. Student's $t$ test: ${ }^{*}, P<0.05 ;{ }^{*}{ }^{*}, P<0.01$. (E-G) Analysis of the interaction of $\mathrm{kaB}-\mathrm{RAF}$ with other signaling pathways in the E12.5 nervous system. Representative Western blots are from three independent experiments, each with two or three E12.5 embryos for each genotype. (G) B-RAF protein levels are not increased in E12.5 DRG and spinal cord of LSL-kaBraf:nesCre embryos and control littermates. Molecular mass is indicated in kilodaltons. $(H)$ Representative images of nerve endings in trunk skin of E13.5 embryos. Bars: (B) $200 \mu \mathrm{m}$; (H) $40 \mu \mathrm{m}$. (I) The number of branches per nerve trunk was quantitated, blinded to the genotypes, for a defined skin section by counting the total number of branch points observed along each major nerve trunk entering the skin (Zhong et al., 2007). $n=3$ for each group. (D and I) Error bars indicate SEM. activation of intraneuronal RAF-MEK signaling is sufficient to promote robust axon growth in developing and regenerating neurons in the peripheral nervous system and CNS.

\section{RESULTS}

Activation of B-RAF signaling alone is sufficient to promote sensory axon extension during early development

In vivo, the neurotrophin nerve growth factor (NGF) signals through its receptor kinase TrkA to promote developmental extension of dorsal root ganglion (DRG) nociceptive TrkA ${ }^{+}$ peripheral axons into the epidermis. To examine whether RAF signaling alone is sufficient to promote long-range axon extension of TrkA-positive neurons, we set out to selectively activate RAF kinase signaling in these neurons in a TrkAnull background.

To this end, we first conditionally activated RAF signaling in a WT background using a genetically modified loxP-STOPloxP-Braf ${ }^{V 600 E}$ (LSL-kaBraf) knock-in mouse line (Mercer et al., 2005), in which a kinase-activated B-RAF (kaB-RAF) mutant is expressed from the endogenous B-RAF locus upon Cre recombination. We next bred $L S L$-kaBraf mice with a neuronal 
Article

A
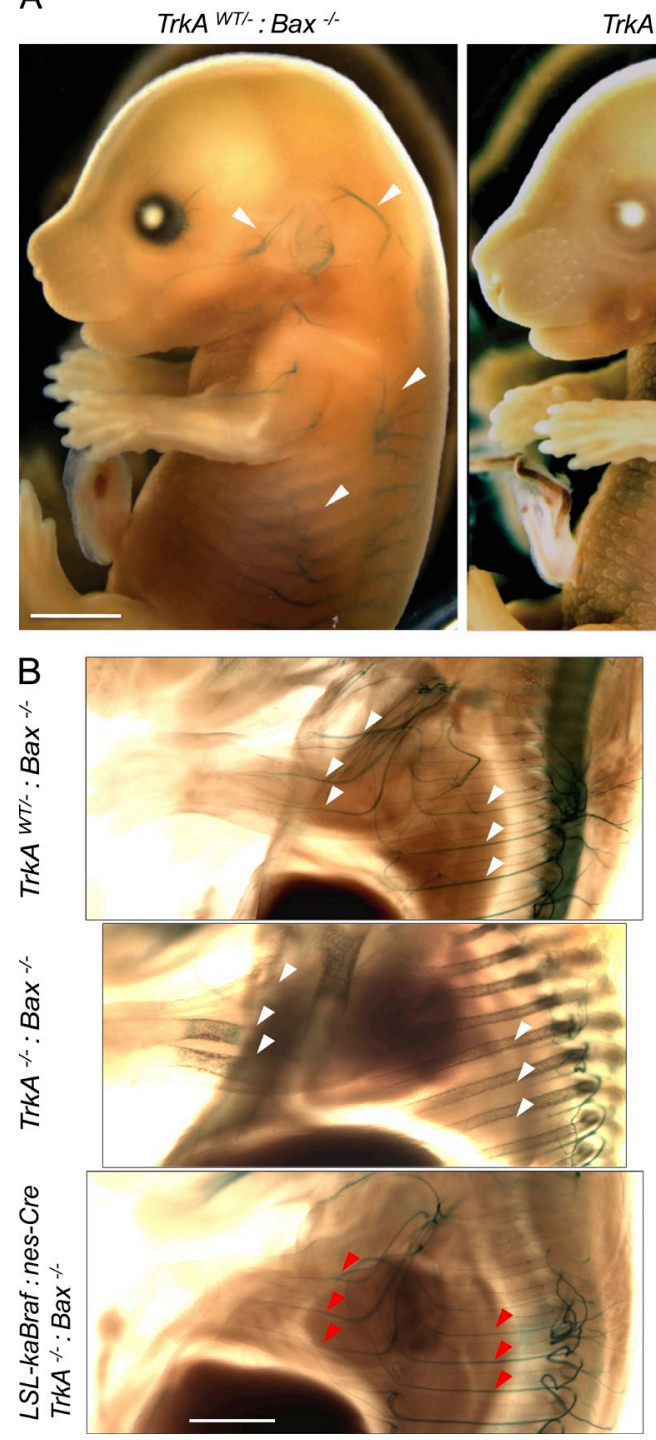

$\operatorname{TrkA} \%:$ Bax $^{\%}$

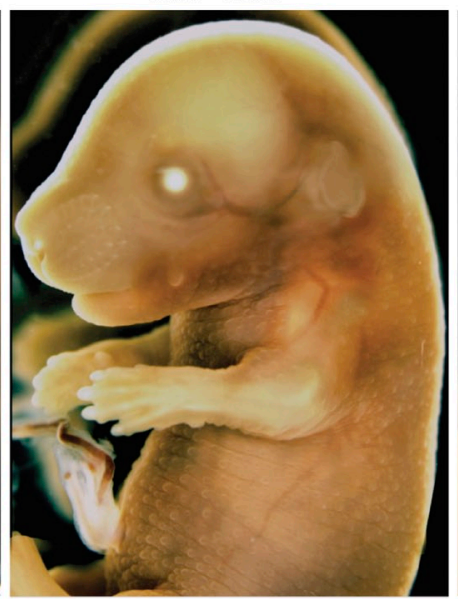

LSL-kaBraf: nes-Cre $\operatorname{TrkA} A^{\varkappa}: B a x$

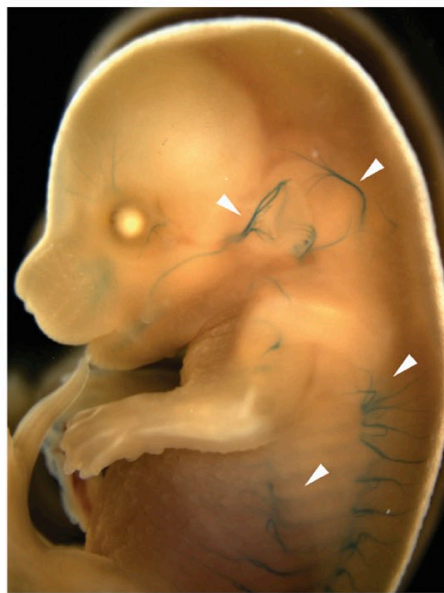

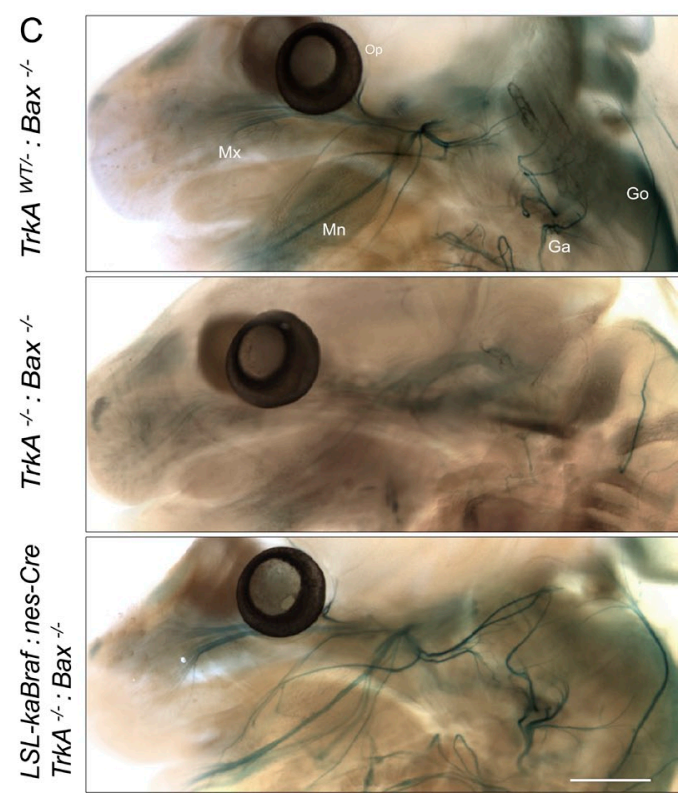

Figure 2. Expression of kaB-RAF substantially rescues sensory afferent growth in the absence of TrkA/NGF signaling. (A, left) Normal sensory cutaneous innervation at E16.5. (middle) Sensory cutaneous innervation is lost in embryos lacking the NGF receptor TrkA. (right) Expression of kaB-RAF restores cutaneous innervation. Arrowheads label the blue $\beta$-gal-positive (presumptive TrkA ${ }^{+}$) sensory trajectories. (B) Visualization of axon growth patterns after tissue clearing. The thoracic somatosensory innervation driven by kaB-RAF in a TrkA $A^{-/-}$embryo (bottom; compare with middle for TrkA $A^{-/-}$ alone) is similar to that seen in a control TrkA $A^{W T-}$ littermate (top). White arrowheads indicate the normal pathways of peripheral axons extending from thoracic DRGs. Red arrowheads indicate sensory projections rescued by kaB-RAF in the TrkA $A^{-1}$ background. (C) Expression of kaB-RAF substantially rescues trigeminal TrkA+ afferent growth in the absence of TrkA/NGF signaling. Presumptive TrkA+ trigeminal axon projections (top) are lost in TrkA-deficient mice (middle) and are rescued by kaB-RAF (bottom). Ga, great auricular nerve; Go, greater occipital nerve; Mn, mandibular branch; $\mathrm{Mx}$, maxillary branch; Op, ophthalmical branch. Images show littermates and are representative of three embryos per genotype. Bars: (A) $2 \mathrm{~mm}$; (B and C) $1 \mathrm{~mm}$.

nestin promoter-driven Cre deleter (nes-Cre; Tronche et al., 1999). In DRG neurons, nes-Cre-mediated recombination occurs as early as embryonic day (E) 11.5 (Galabova-Kovacs et al., 2008). Embryos heterozygously expressing kaB-RAF progressively developed macrocephaly from E13.5 onwards (Fig. 1 A) but appeared otherwise normal, including normally sized DRGs (Fig. 1 B). The known RAF effectors were activated in neuronal tissues expressing Cre recombinase, as indicated by elevated phospho-MEK1/2 (pMEK1/2) and pERK1/2 in the neocortex and spinal cord of E12.5 LSL-kaBraf:nes-Cre mice
(Fig. 1, C and D). Note that compared with MEK1/2, ERK1/2 activation appears minor in the kaB-RAF-expressing DRGs; this is because of relatively high levels of $\mathrm{pERK} 1 / 2$ in the DRG at baseline. B-RAF activation did not affect mTOR phosphorylation (Fig. 1 E). Levels of pAKT, pS6K, and pGSK3 $\beta$ were not changed significantly in the DRG of LSL-kaBraf:nes-Cre mice (Fig. 1 F), indicating minimal cross talk between the MAP kinase and PI3-kinase-AKT pathways. Because the expression of kaB-RAF is under the control of endogenous Braf promoter, the expression level of B-RAF protein is not changed in 

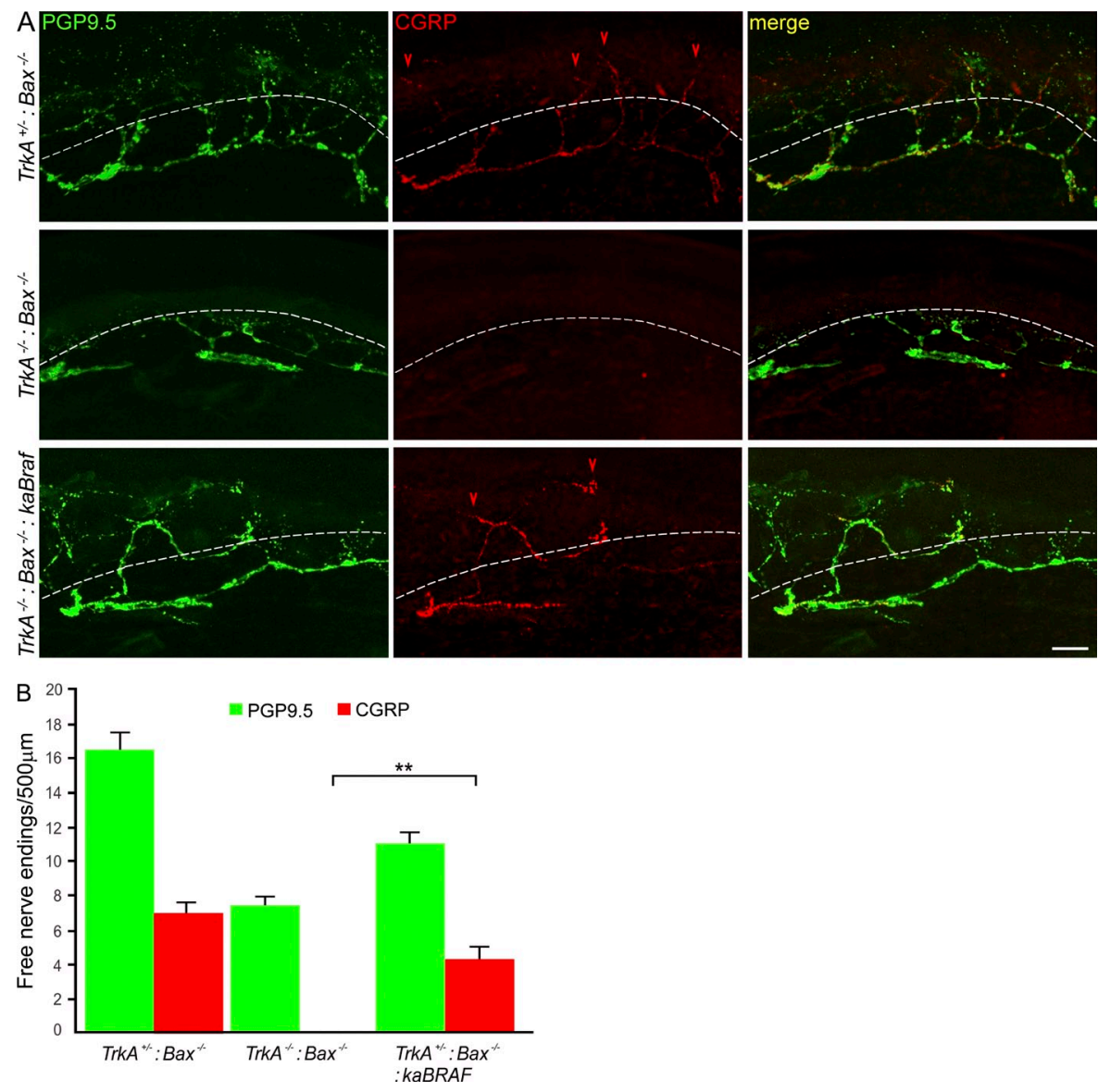

the DRG and spinal cord at E12.5 (Fig. 1 G). At E13.5, the branching pattern of sensory nerves in the skin was not changed by kaB-RAF expression (Fig. 1, H and I).

\section{B-RAF activation rescues nociceptor axon extension in embryos lacking TrkA}

To test whether kaB-RAF is sufficient to drive nociceptor axon growth in the absence of TrkA signaling, we next mated the LSL-kaBraf:nes-Cre line with available TrkAtaulac and

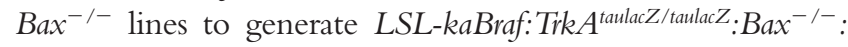
nes-Cre mice. In Trk $A^{\text {taulac } Z}$ mice, the WT TrkA gene is replaced by a taulac $Z$ expression cassette, such that the axonal morphology of putative $\operatorname{Trk} \mathrm{A}^{+}$neurons can be visualized by $\beta$-gal staining (Moqrich et al., 2004). Because TrkA expression is absent in homozygous $\operatorname{Trk} A^{\text {taulac } Z \text { /taulac } Z}$ mice, we refer

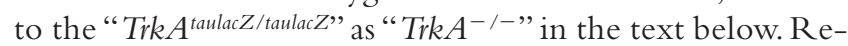
moval of the Bax gene blocks apoptosis in embryonic DRG neurons, rescuing them from cell death that is otherwise observed in the absence of TrkA signaling. The $B a x^{-1-}$ background thus allows for the molecular dissection of signaling pathways that specifically affect axon growth (Knudson et al., 1995; Lentz et al., 1999; Patel et al., 2000; Markus et al., 2002; Kuruvilla et al., 2004; Moqrich et al., 2004). In Trk $A^{-\prime-}$ : $B a x^{-1-}$ mice, DRG neurons survive, but sensory afferent innervation in the skin is completely abolished (Fig. 2, A and B, middle; Patel et al., 2000). Compared with control littermates
Figure 3. Axon terminal innervation of E18.5 footpad. (A, top) Normal innervation. (middle) In the absence of TrkA, innervation is diminished overall, and the CGRP-positive nociceptor endings are completely absent. Red arrowheads indicate the CGRP-positive axon terminals in the epidermis. (bottom) kaB-RAF expression partially rescues nociceptive innervation in the TrkA-I- background. The dashed lines indicate the dermal-epidermal border. Bar, $100 \mu \mathrm{m}$. (B) Quantification of axon innervation in footpad (Luo et al., 2007; Hancock et al., 2011). Data are from three fetuses per genotype. Error bars indicate SEM. One-way ANOVA with post-hoc Tukey's HSD test: ${ }^{*}, \mathrm{P}<0.01$. (which include LSL-kaBraf:Trk $A^{-1-}: B a x^{-1-}$, nes-Cre:Trk $A^{-1-}$ : $B a x^{-1-}$, and Trk $A^{-1-}: B a x^{-/-}$genotypes), in which we detected no LacZ-positive fibers in the skin at E16.5, expression of kaBRAF in Trk $A^{-/-}: B a x^{-1-}$ DRG and trigeminal neurons substantially restored cutaneous sensory axon projections (Fig. 2, A-C). The morphologies of the radial thoracic trajectories derived from spinal DRGs as well as those growing from trigeminal ganglia induced by $\mathrm{kaB}-\mathrm{RAF}$ in the $\operatorname{Tr} A^{-1-}: B a x^{-1-}$ background were grossly similar to those seen in control mice. Epidermal innervation of the footpad was partially rescued by kaB-RAF (Fig. 3, A and B). Thus, sustained B-RAF kinase activity can, to a large extent, substitute for TrkA-mediated axon growth signaling in presumptive $\operatorname{Trk} \mathrm{A}^{+}$sensory neurons.

\section{B-RAF-mediated axon growth indirectly rescues calcitonin gene-related peptide (CGRP) expression in $\mathrm{TrkA}^{-/-}: \mathrm{Bax}^{-/-}$neurons}

CGRP expression in the peptidergic subset of nociceptive DRG neurons is induced by skin-derived factors and therefore indicates that sensory axon peripheral innervation into the skin is complete (Hall et al., 1997, 2001; Patel et al., 2000; $\mathrm{Xu}$ and Hall, 2007). In Trk $A^{-/-}: B a x^{-/-}$mice, DRG neurons and their centrally projecting axons are devoid of CGRP because of the lack of cutaneous innervation as previously described (Patel et al., 2000), whereas CGRP expression in the spinal motor neurons remains unaffected (Fig. 4 A, middle). 
A
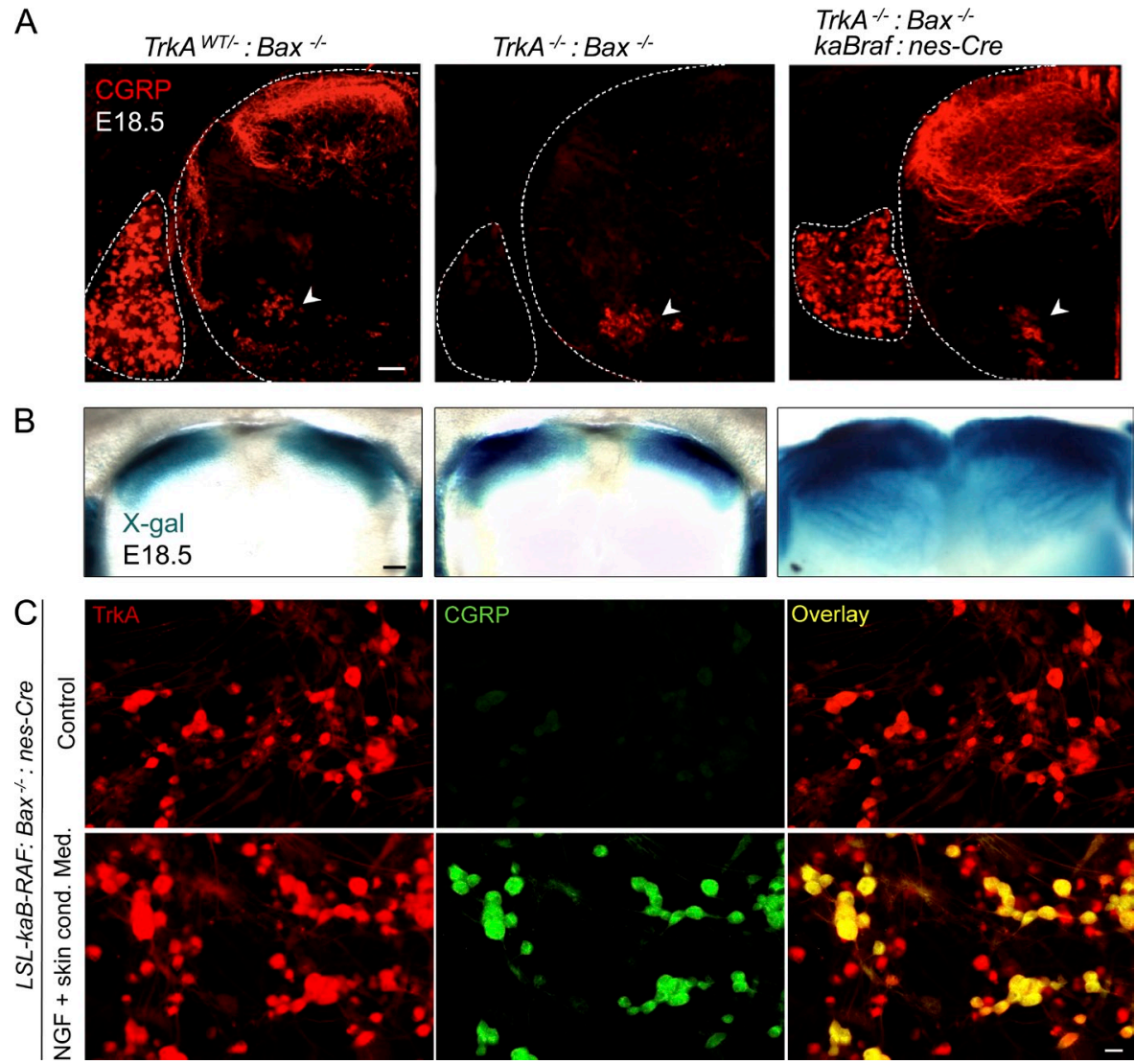

Figure 4. Activation of $\mathrm{B}-\mathrm{RAF}$ indirectly rescues CGRP expression in TrkA-/- nociceptive neurons. (A, left) Normal CGRP staining in the DRG and superficial dorsal horn. Arrowhead indicates CGRP-expressing spinal motoneurons. (middle) CGRP expression is completely abolished in the DRG and its projections in TrkA/Bax double-null mice. CGRP staining in spinal motoneurons is not affected by loss of TrkA signaling (arrowhead). (right) CGRP expression in DRG is rescued by expression of kaB-RAF, in the absence of TrkA signaling (LSL-kaBraf:nes-Cre:TrkA-1- :Bax-1-). Arrowhead indicates the CGRP+ motor neurons. Dashed white lines outline the spinal cord and DRG. (B) The nociceptive projection into the dorsal horn (left) does not depend on TrkA (middle). Expression of kaB-RAF causes overgrowth and ectopic targeting of these fibers (right). ( $A$ and $B$ ) Images are representative of three embryos each. (C) Activation of B-RAF does not directly induce CGRP expression in cultured DRG neurons. (top) No CGRP is expressed in 7-d in vitro cultures of dissociated E12.5 LSL-kaBraf:Bax ${ }^{-1-}$ :nes-Cre DRG neurons. (bottom) NGF and conditioned medium from skin cultures are necessary to induce CGRP expression in E12.5 LSL-kaBraf:Bax ${ }^{-1-}$ : nes-Cre DRG neurons. Images are representative of three independent experiments. This experiment has been repeated three times. Each experiment used two embryos per genotype. Bars: (A and B) $100 \mu \mathrm{m}$; (C) $20 \mu \mathrm{m}$.
B-RAF gain-of-function restored CGRP expression in the absence of TrkA (Fig. 4 A, right). Note also that in contrast to the projections in the periphery, the growth of presumptive TrkA-positive afferent projections in the dorsal horn is independent of TrkA signaling (Fig. 4 B, middle; Patel et al., 2000; Harrison et al., 2004) and that kaB-RAF expression caused overgrowth of these afferents (Fig. 4 B, right) but not of peripheral projections (Fig. 1). In vitro, kaB-RAF alone did not induce CGRP expression in DRG neurons (Fig. 4 C, top); this required the addition of NGF and skin-conditioned medium as previously reported (Fig. 4 C, bottom; Hall et al., 1997; Patel et al., 2000; Xu and Hall, 2007). In addition, we have shown previously that loss of both B- and C-RAF in DRGs does not abrogate the CGRP expression (Zhong et al., 2007). These data together indicate that the restoration of CGRP expression in LSL-kaBraf:nes-Cre:Trk $A^{-/-}: B a x^{-/-}$DRG neurons is not directly caused by the elevation of neuron-intrinsic B-RAF activity, but indirectly through the restoration of cutaneous innervation and subsequent retrograde signaling from skin-derived factors.

\section{kaB-RAF causes overgrowth of nociceptive} and proprioceptive afferent fibers in the spinal cord In WT mice, different subpopulations of sensory neurons project from the DRG to highly specific targets in the spinal cord.
Specifically, nociceptive $\operatorname{Trk} \mathrm{A}^{+}$fibers terminate in the superficial laminae I and II of the dorsal horn, and proprioceptive parvalbumin-positive afferents project to intermediate laminae or to the ventral spinal cord.

In B-RAF gain-of-function mice, we observed excessive growth of both nociceptive and proprioceptive afferents (Fig. 5). Nociceptive axons normally restricted to superficial dorsal horn extended ectopically into deeper layers of dorsal spinal cord, and many axons aberrantly crossed the midline (Fig. 5 A). This kaB-RAF-driven overgrowth was substantially rescued by concomitant elimination of MEK1/2, the canonical downstream kinases of RAF (Fig. 5 C), suggesting that the effect of kaB-RAF expressed from the endogenous Braflocus depends strictly on canonical signaling.

In WT mice, the central proprioceptive afferents enter the cord medially at tightly circumscribed dorsal root entry zones (DREZs; Fig. 5 B, left). kaB-RAF expression caused the proprioceptive sensory axons to enter the spinal cord all across its surface and to aberrantly terminate some branches in the superficial dorsal laminae (Fig. 5 B, right). Proprioceptive axons in the DREZs normally are subject to repulsive guidance from Semaphorin 6C/D (Sema6) expressed in the spinal cord, acting on PlexinA1 on the sensory axons (Yoshida et al., 2006). kaB-RAF expression did not detectably alter the protein (Fig. 5 D) or transcript levels (RNAseq; not depicted) 

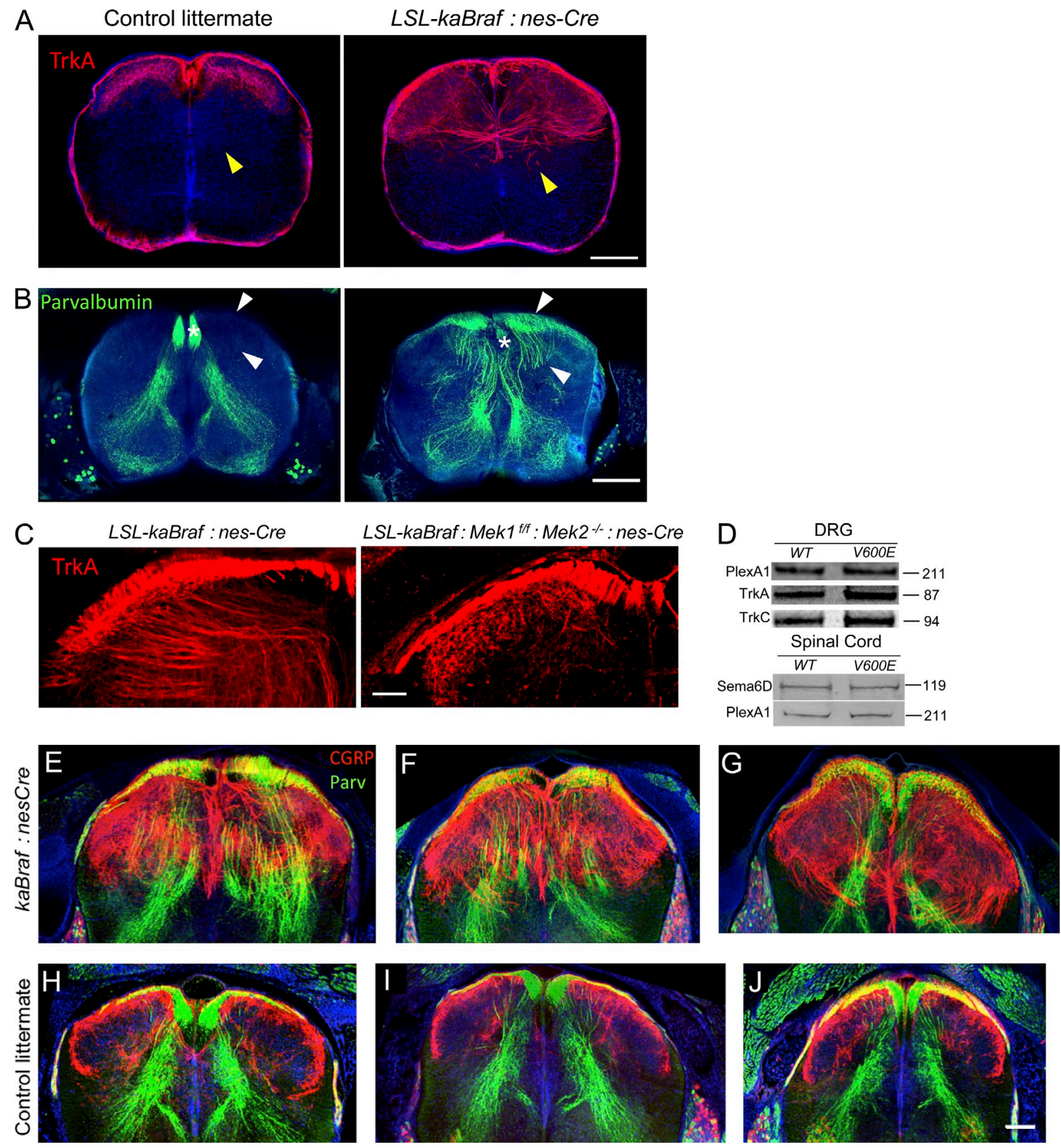

Figure 5. Activation of B-RAF drives overgrowth of centrally projecting nociceptive and proprioceptive DRG axons in the E18.5 spinal cord. (A) Nociceptive projections stained for TrkA. Yellow arrowheads indicate the different patterns of axon projections of WT and kaB-RAF-expressing, nociceptive neurons. (B) Proprioceptive projections stained for parvalbumin. White arrowheads indicate the different patterns of axon projections of WT and kaB-RAF-expressing, proprioceptive neurons. Asterisks label the presumptive DREZs. (C) kaB-RAF-driven overgrowth of central nociceptive projections (left) is abolished in the absence of the downstream effectors MEK1/MEK2 (right). (A-C) $n=3$ per genotype. (D) kaB-RAF does not affect the expression of known guidance cues PlexinA1 and Sema6D in the E12.5 DRG and spinal cord. Western blot is representative of three independent experiments, each with two embryos per genotype. Molecular mass is indicated in kilodaltons. (E-J) Cross sections of P0 spinal cord at cervical $(\mathrm{E}$ and $\mathrm{H})$, thoracic ( $\mathrm{F}$ and $\mathrm{I})$, and lumbar ( $\mathrm{G}$ and J) levels were stained for CGRP, parvalbumin (Parv), and Draq5 (blue). Bars: (A and B) $200 \mu \mathrm{m}$; (C) $100 \mu \mathrm{m}$; (E-J) $50 \mu \mathrm{m}$.

of these factors in E12.5 DRG and spinal cord. The overgrowth phenotype for both nociceptive and proprioceptive afferents was observed at all levels of the spinal cord (Fig. 5, E-J). This phenotype suggested that reactivation of the B-RAF pathway in injured adult neurons might be exploited to promote regeneration. 

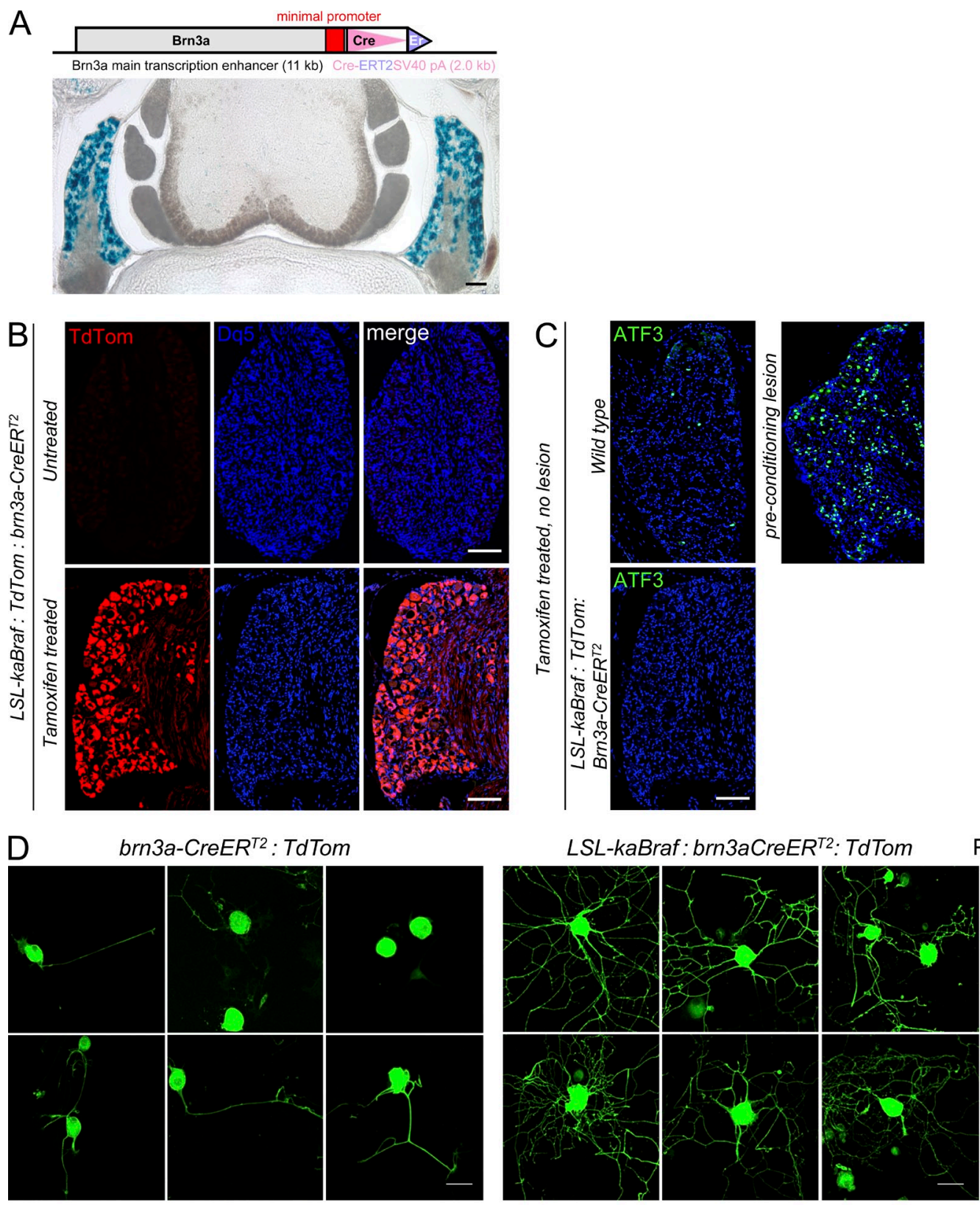

Pre-conditioning lesion
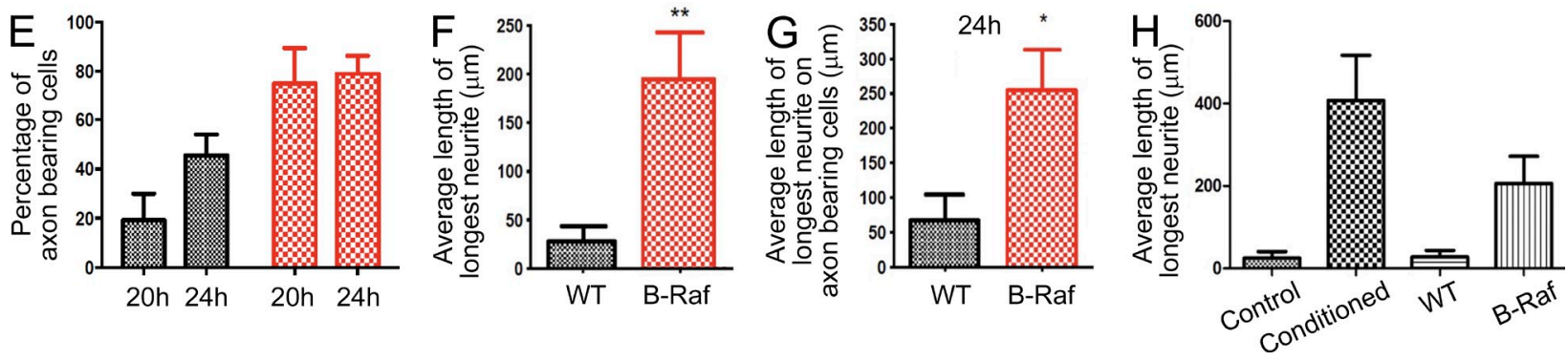

Figure 6. Activation of B-RAF signaling in mature DRG neurons elevates their growth competency. (A, top) Schematic of the brn $3 a-C r e E R^{T 2}$ construct used to generate the brn3a-CreERT2 deleter mouse line. (bottom) A cross section of the spinal cord of a 10-wk-old Rosa26-lacZ:brn3aCreER ${ }^{T 2}$ mouse treated with tamoxifen. Blue LacZ staining indicates CreER ${ }^{T 2}$-medicated recombination in the DRG neurons. (B) Representative DRGs from adult LSL-kaBraf:TdTom:brn3a-CreER ${ }^{T 2}$ mice without (top left) and with (bottom left) tamoxifen treatment. TdTom expression indicates recombination in DRG neurons. Cells were counterstained with Draq5 (Dq5) to label nuclei. (C) ATF3 is induced by preconditioning lesion. Blue shows nuclear stain Draq5. (D) Representative images of adult DRG neurons derived from intact brn3a-CreER ${ }^{T 2}$ :TdTom (left), LSL-kaBraf:brn3aCreER ${ }^{T 2}$ :TdTom 

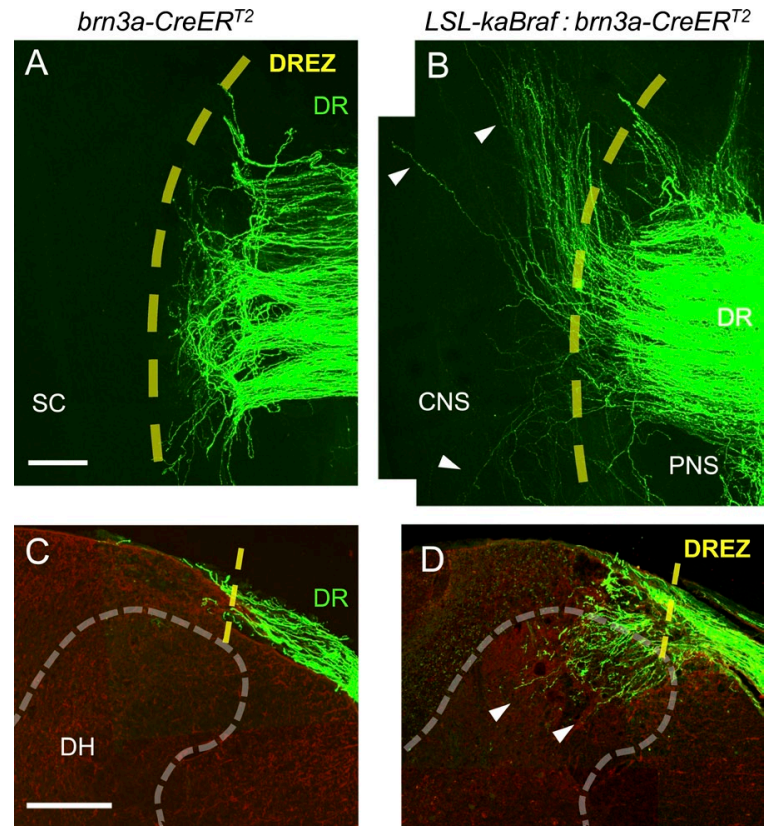

Figure 7. Activation of B-RAF signaling enables crushed sensory axons to regenerate into adult spinal cord. (A-D) Confocal views of regenerating dorsal root axons in whole mounts ( $A$ and $B$ ) or transverse sections ( $C$ and $D) 2$ wk after root crush. Axons were labeled by AAV-GFP injected into $\mathrm{C} 6$ and $\mathrm{C} 7 \mathrm{DRGs}$ at the time of the crush injury. ( $\mathrm{A}$ and $\mathrm{C}$ ) Control mice (brn3a-CreER ${ }^{T 2}$ ). (B and D) Mice expressing activated B-RAF in DRGs (LSL-kaBraf:brn3a-CreER ${ }^{T 2}$ ). Dashed yellow lines indicate the DREZ, dashed gray lines indicate the border between gray and white matter, and arrowheads indicate the extent of axon growth across the DREZ (B) and into gray matter (D). DH, dorsal horn; DR, dorsal root; PNS, peripheral nervous system; SC, spinal cord. $n=2$ DRGs from each of three animals per genotype. Bars, $200 \mu \mathrm{m}$.

\section{kaB-RAF enables regeneration of injured adult DRG central axons across the DREZ}

To test whether activation of B-RAF signaling can drive mature sensory axon regeneration, we generated LSL-kaBraf: TdTomato (TdTom):brn3a-CreER $R^{T 2}$ mice to inducibly express kaB-RAF in adult DRG neurons. The brn3a-CreER ${ }^{T 2}$ deleter mouse line was generated using a brn3a promoter (Eng et al., 2001), which mediates expression selectively in sensory neurons (Fig. $6 \mathrm{~A}$ ). We first assessed B-RAF gain-of-function in cultured adult neurons. 12-wk-old mice were treated with tamoxifen for a consecutive $5 \mathrm{~d}$ to induce kaB-RAF expression, as indicated by TdTom expression (Fig. 6 B). ATF3, a marker whose expression is triggered by conditioning lesion (Smith and Skene, 1997; Seijffers et al., 2007) was not induced (Fig. 6 C). DRG neurons were cultured for up to $24 \mathrm{~h}$. kaBRAF expression correlated with both greatly increased numbers of axon-bearing neurons and increased total axon length with more branching compared with that of WT neurons (Fig. 6, D-G). Furthermore, the axonal morphology of kaBRAF-expressing neurons differs from WT neurons subject to a preconditioning lesion, which exhibited single long axons (Fig. 6, D and H).

Having thus ascertained the functionality of the $L S L$ kaBraf:TdTom:brn3a-CreER ${ }^{T 2}$ mouse line, we next tested whether kaB-RAF can enable axon regeneration after dorsal root crush injury in vivo. $12-$ wk-old mice were again treated with tamoxifen for a consecutive $5 \mathrm{~d}$. After $2-\mathrm{d}$ rest, C5-8 cervical roots were crushed and AAV2-GFP was injected to C6 and C7 DRGs to label regenerating sensory axons. After 2 wk, regeneration in the C6 and C7 roots and spinal cord was examined in whole-mount preparations (Fig. 7, A and B) or in transverse sections (Fig. 7, C and D). As expected, in control brn3a-CreER ${ }^{T 2}$ mice (Fig. 7, A and C), axons regenerated along the roots but stopped at the DREZ. In contrast, in mice with kaB-RAF expression in DRG neurons, numerous axons penetrated the DREZ and grew deeply into the spinal cord, exhibiting dense collateral branches in the dorsal column (Fig. 7 B) and reaching superficial laminae of the dorsal horn (Fig. 7 D). Thus, elevation of intrinsic B-RAF signaling is sufficient, both in vitro and in vivo, to induce robust axon regrowth of adult DRG neurons and, importantly, renders the axons capable of overcoming growth-inhibitory signals that are abundant at the DREZ and within the spinal cord.

\section{kaB-RAF enables regenerative axon growth in the injured optic nerve through an MEK-dependent pathway}

To test whether activation of B-RAF kinase signaling can promote axon regeneration of injured mature CNS neurons, we used an optic nerve regeneration model (Fig. 8, A and B; Park et al., 2008; Benowitz andYin, 2010). 8-12-wk-old LSL-kaBraf: $B a x^{-1-}$ mice and $B a x^{-1-}$ controls were injected intravitreally with AAV2-Cre to induce kaB-RAF expression in retinal ganglion cells (RGCs) and then subjected to optic nerve crush. The $B a x^{-1-}$ background was used to minimize apoptotic death of retinal ganglion neurons triggered by optic nerve injury, which may amount to $80 \%$ at 2 wk after optic nerve crush (Li et al., 2000). 2 wk after the injury, we observed robust regenerative axon growth up to $3 \mathrm{~mm}$ past the lesion site in the kaB-RAFexpressing optic nerve (Fig. 8,D and G), with very limited growth in the control Bax ${ }^{-/-}$littermates (Fig. $8 \mathrm{C}$ ), consistent with previous observations that survival alone is not sufficient to promote growth of adult RGC axons (Goldberg et al., 2002).

Combined deletion of the canonical RAF effector kinases MEK1 and MEK2 substantially suppressed the regenerative axon growth caused by kaB-RAF (Fig. 8 E), indicating that kaB-RAF drives axon growth through the canonical MEK effectors. Whereas the length of axon extension induced by

(middle), and WT preconditioning lesioned mice (right) after $24 \mathrm{~h}$ in vitro. TdTom is shown in green to improve contrast. Bars: (A-C) $100 \mu \mathrm{m}$; (D) $20 \mu \mathrm{m}$. (E-H) Quantitation of axon extension in adult DRG cultures at $24 \mathrm{~h}$ in vitro. Data were collected from three independent experiments from three animals per genotype or condition and analyzed as described previously (Parikh et al., 2011); >100 cells were counted per group. Error bars indicate SEM. One-way ANOVA with post-hoc Tukey's HSD test: ${ }^{*}, \mathrm{P}<0.01 ;{ }^{* *}, \mathrm{P}<0.005$. 


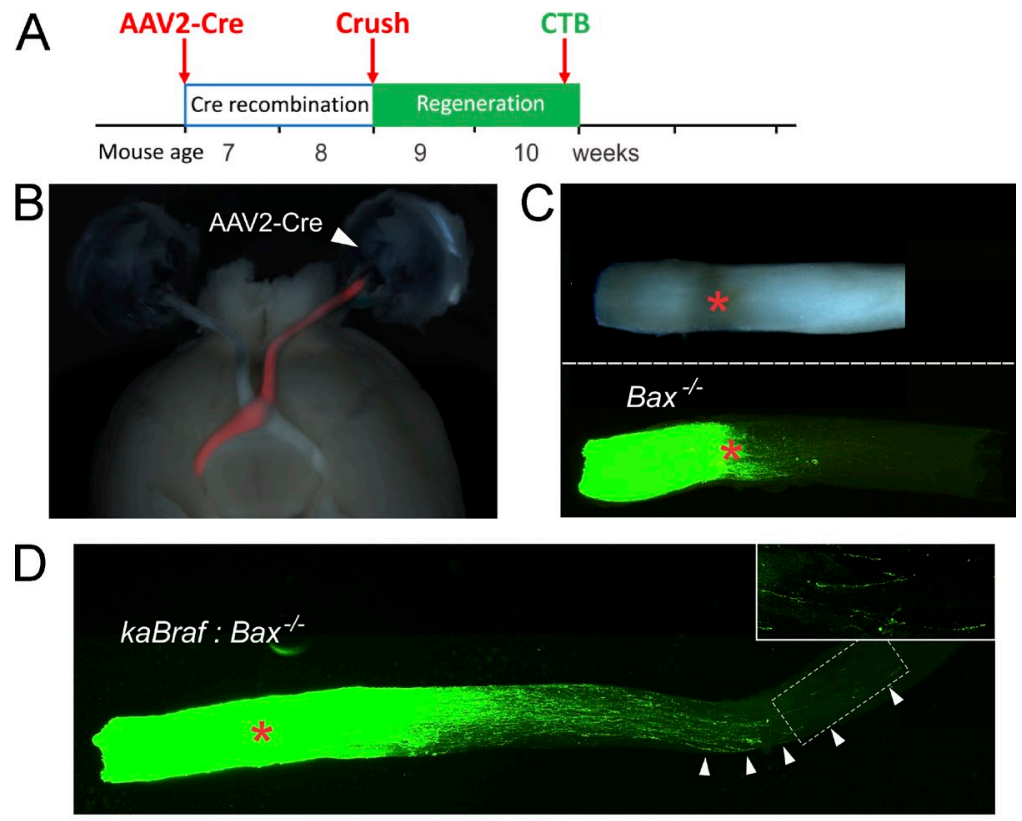

E

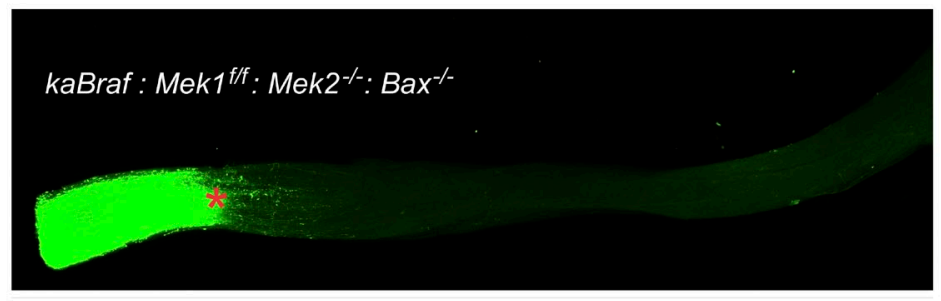

$\mathrm{F}$

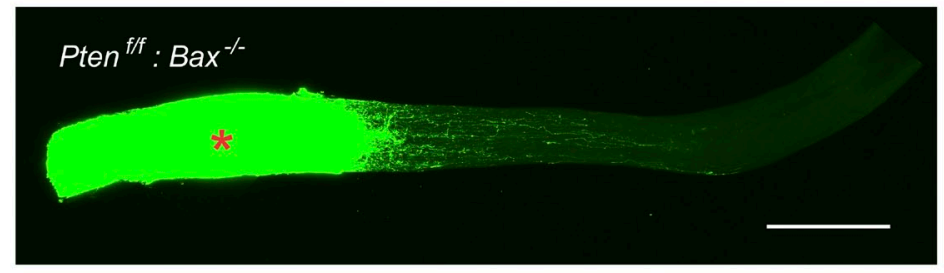

$\mathrm{G}^{180}$

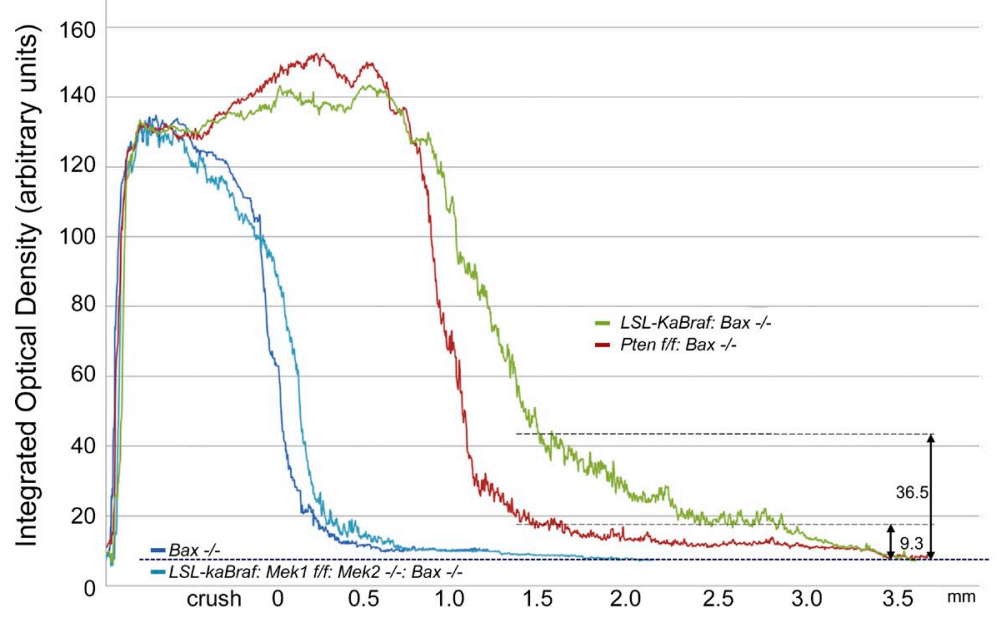

Figure 8. Activation of B-RAF enables regenerative axon growth in the crush-lesioned optic nerve via the canonical effectors MEK1/2. (A) Schematic of experimental time course. (B) Intravitreal injection of AAV2-Cre induces expression of TdTom in retinal ganglion neurons, labeling the entire optic nerve (red). (C, top) Whole-mount image of a crushed $\mathrm{Bax}^{-/-}$optic nerve. Crush site is indicated by a red asterisk here and in all following panels. (bottom) Confocal fluorescence image of the same nerve. Green shows axons anterogradely labeled with CTB-Alexa Fluor 488. (D) Wholemount confocal imaging shows strong regenerative growth in the lesioned kaB-RAF-expressing optic nerve. (inset) Axons at $\sim 3.5 \mathrm{~mm}$ from the crush site (magnified from the boxed area). Arrowheads indicate outgrowing axons. (E) Loss of MEK1 and MEK2 abolishes the regeneration driven by kaB-RAF. (F) Optic nerve regeneration in the absence of PTEN. Bar, $0.5 \mathrm{~mm}$. (C-F) Images are representative of three optic nerves per genotype. $(G)$ Quantitation of axon regenerative growth in the optic nerve 2 wk after nerve crush; genotypes as shown in B-E. At $\sim 1.6 \mathrm{~mm}$ from the crush site, the density of regenerating axons is more than threefold greater in the LSL-kaBraf:Bax ${ }^{-/}$genotype than in the Pten $^{f / f}: \mathrm{Bax}^{-/-}$ genotype. Data are from three nerves per genotype. Optic densities were acquired from the whole-mount optic nerves using an LSM710NLO two-photon confocal microscope with the ZEN2009 software. Data were normalized by setting the baseline $O D$, as measured $0.2 \mathrm{~cm}$ proximal to the crush site in all nerves, to the same (arbitrary) level.
B-RAF gain-of-function is comparable with the maximal axon growth reported in PTEN deletion mice (Fig. 8 F; Park et al., 2008), in a direct comparison, we found up to a 3.9-fold higher density of regenerating axons in the LSL-kaBraf:Bax ${ }^{-1-}$ mice $1.5 \mathrm{~mm}$ distal to the crush site than is seen in the crushed Pten $^{-1-}:$ Bax $^{-/-}$optic nerve (Fig. 8, D, F, and G). 

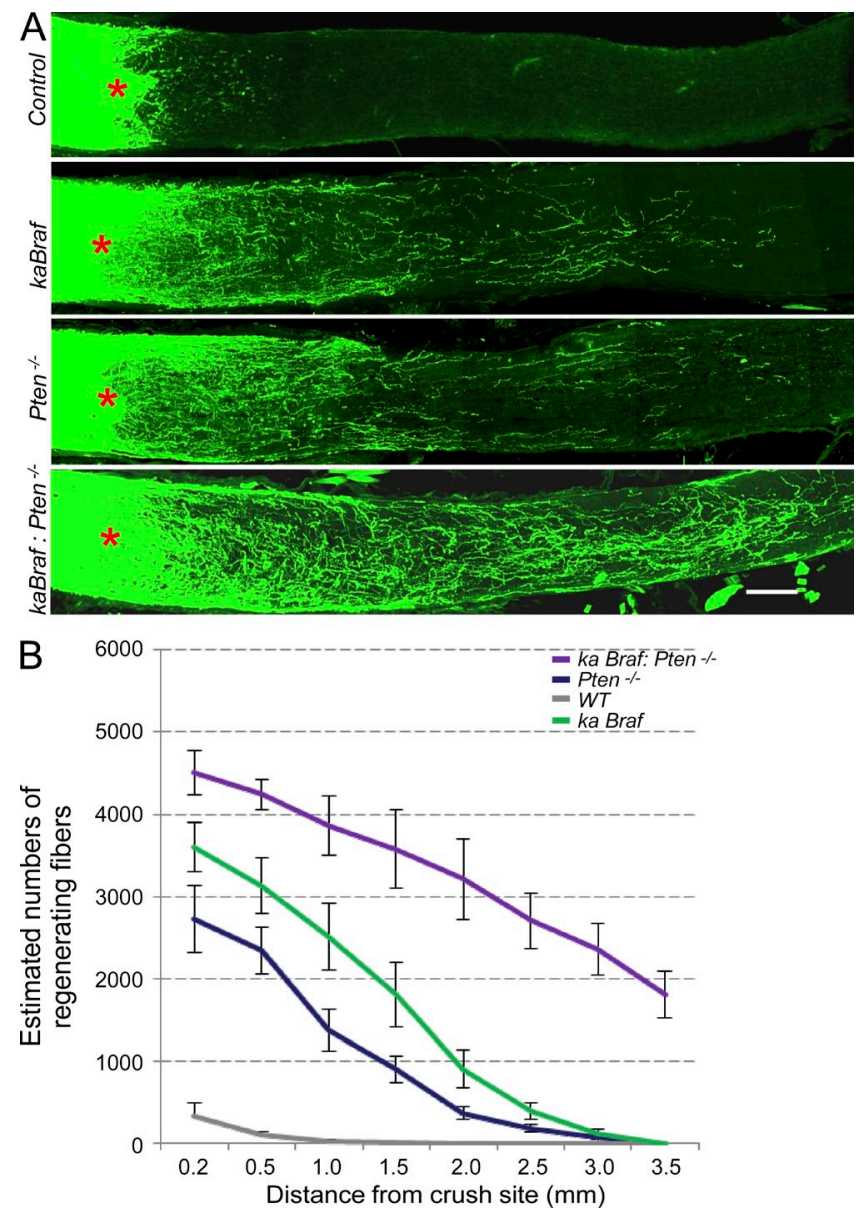

Figure 9. Combined B-RAF activation and PTEN deletion enables long-range axon regeneration. (A) Representative longitudinal sections of regenerating optic nerve 2 wk after crush injury. Genotypes are as indicated. Crush site is indicated by a red asterisk. Bar, $200 \mu \mathrm{m}$. (B) Quantitation of data as shown in A. Axons were counted as described in Park et al. (2008). $n=6$ nerves per genotype. Error bars indicate SEM. Twoway ANOVA tests comparing LSL-kaBraf with Pten ${ }^{f / f}, L S L-k a B r a f$ and Pten $^{f / f}$ with WT, or LSL-kaBraf and Pten ${ }^{f / f}$ with LSL-kaBraf:Pten ${ }^{f / f}$ all resulted in $p$-values $<0.001$.

\section{kaB-RAF expression and PTEN deletion synergize to increase axon regenerative growth}

To test whether combined activation of the B-RAF and PI3kinase-mTOR pathways can further boost axon growth capacity in injured adult retinal ganglion neurons, we performed the optic nerve regeneration experiments using double $L S L$ kaBraf:Pten f/f mice. Both the numbers and length of regenerating axons were increased in the optic nerve of the LSL-kaBraf: Ptenfff mice compared with those in single LSL-kaBraf or in Pten fff mice (Fig. 9 A). The synergistic effect of activating both $\mathrm{B}-\mathrm{RAF}$ and PI3-kinase signaling is most apparent at the longest lengths of axon regeneration (Fig. $9 \mathrm{~B}$ ). Note that the mice in these experiments were from a Bax WT background to enable direct comparison with the original PTEN deletion data (Park et al., 2008); however, this means that possible survivalpromoting effects of the mutant alleles cannot be excluded.

\section{DISCUSSION}

An understanding of the mechanisms that drive axon growth is important, both to decipher how connectivity develops in the nervous system and to develop therapeutic strategies for nervous system repair after injury or disease. We show that the RAF-MEK axis plays a key role in axon growth signaling. Activation of B-RAF in neurons is sufficient to drive sensory axon growth in the embryo, to enable adult sensory axons to regenerate across the DREZ and further into the spinal cord, and to induce robust regeneration of adult retinal axons in the injured optic nerve. Both developmental DRG axon overgrowth in the spinal cord and mature RGC axon regeneration in the optic nerve were abrogated by concomitant ablation of MEK1 and MEK2. We thus establish classical cellautonomous RAF-MEK signaling as a fundamental driver of axon growth. We should note that this pathway seems to be selective to axon growth signaling because we have never observed that B-RAF activation supports neuronal survival (unpublished data).

In vitro work has long suggested a potential role for RAFMEK signaling in axon growth. Previous in vivo data, however, have been scarce and controversial. In the retina, for example, pharmaceutical inhibition of MEK-ERK signaling abrogated optic nerve regeneration supported by FGF2 (Sapieha et al., 2006). Two putative intracellular activators of RAF signaling, BAG1 and Mst3b, have been shown to promote regenerative axon growth in the optic nerve (Planchamp et al., 2008; Lorber et al., 2009), but the expression of a constitutively active MEK1 did not drive any regeneration in the optic nerve (Pernet et al., 2005). Others have concluded that ERK activity promotes RGC axon regeneration via an indirect mechanism dependent on glial cells (Müller et al., 2009). Although it is likely that multiple mechanisms, direct as well as indirect, will contribute to axon regeneration in the inhibitory environment of the CNS, the current cacophonic state of the field is likely caused by the mainly indirect approaches of incomplete penetrance that have been taken by various laboratories. When using small molecule inhibitors or transient viral overexpression of interfering or activating constructs, it is difficult to accurately titrate the dose for the entire duration of an experiment. We believe that we have applied a stringent approach toward activation of RAF signaling in RGCs, and our data argue strongly for a direct positive effect of RAF-MEK signaling on axon growth and regeneration of RGCs, as well as in DRG neurons. Possible downstream mechanisms beyond the MEK kinases remain speculative at this point. Stabilization of microtubules improves axon regeneration in a spinal cord injury (SCI) model through both neuron-intrinsic and -extrinsic mechanisms (Hellal et al., 2011), and it is likely that activation of RAF-MEK signaling will directly affect microtubule stability in injured axons via its effects on microtubule-regulating enzymes such as HDAC6 (Williams et al., 2013). Furthermore, B-RAF has been shown to directly interact with tubulin (Bonfiglio et al., 2011). Activation of $\mathrm{B}-\mathrm{RAF}$ signaling is also likely to trigger the expression of axon growth-enhancing gene sets in injured neurons. The elucidation of exact mechanisms awaits further study. 
The developmental phenotypes we observed in the B-RAF gain-of-function embryos were generally complementary to those previously observed in B-RAF/C-RAF loss-of-function mice (Zhong et al., 2007). In contrast to nociceptors' peripheral projections, the development of their central projections does not depend on NGF/TrkA signaling (Patel et al., 2000; Harrison et al., 2004; Zhong et al., 2007). Notably, we found that activation of B-RAF resulted in overgrowth of both proprioceptive and nociceptive axons in the spinal cord, whereas the expression of two known repulsive signaling molecules in the dorsal cord and DRG, Sema6 and PlexinA1, remained unaltered. Thus, kaB-RAF appears to activate a normally quiescent axon growth signaling pathway in the central sensory axons that seems to be unaffected by repulsive guidance cues.

The importance of this effect, the lack of response to repulsive or inhibitory cues, becomes clear in the context of regeneration of central sensory branches after dorsal root crush injury. Sensory axons expressing kaB-RAF robustly regenerated into the DREZ and spinal cord.

The regeneration failure of DRG axons after dorsal root avulsion injuries has been variously attributed to the lack of intrinsic growth capacity, to extrinsic growth barriers such as glia-associated growth inhibitors at the DREZ, and to premature synaptic differentiation (Han et al., 2012; Smith et al., 2012). Application of neurotrophic factors acting via tyrosine kinase receptors has shown substantially enhanced regeneration (Ramer et al., 2000; Wang et al., 2008; Harvey et al., 2010), even functional recovery with the systemic administration of artemin (Wang et al., 2008), although these results await independent replication. Future studies will test whether a combination of RAF activation with trophic growth factors can further enhance axon regeneration and reinnervation of presumptive targets in the spinal cord.

Compared with spinal cord lesions, the optic nerve's simple structure allows for clear evaluation of both lesion and regeneration. In recent years, the optic nerve model has revealed several intracellular signaling pathways that can drive CNS axon regeneration, most prominently the PI3-kinase-mTOR and the JAK-STAT pathways, engaged by growth factor tyrosine kinase receptors and cytokines (Park et al., 2008; Smith et al., 2009; Buchser et al., 2012; Leibinger et al., 2013; Pernet et al., 2013). Combined deletion of endogenous inhibitors of these two pathways enhanced regeneration above the level reported for deletion of either gene alone (Sun et al., 2011). Activation of PI3-kinase-mTOR via PTEN deletion also enhanced regenerative growth in an SCI model (Liu et al., 2010), suggesting that results obtained in the optic nerve crush model may generally translate to SCI models. Here, we show that the classic growth factor signaling module RAF-MEK enables axon regeneration in the optic nerve at least as powerfully as any previously reported single molecule manipulation and that the combination of kaB-RAF with activation of PI3-kinasemTOR via PTEN deletion enhances optic nerve axon regeneration even more strongly than would be expected for a simple additive effect.
The extent of regeneration achieved by direct genetic activation of specific intracellular signaling pathways, including B-RAF, DLK, PI3-kinase-mTOR, KLF, and JAK-STAT pathways (Smith et al., 2009; Yan et al., 2009; Park et al., 2010; Blackmore et al., 2012; Shin et al., 2012; Lang et al., 2013), compares favorably with what has been reported for application of growth factors such as NGF, BDNF, GDNF, and CNTF (Lykissas et al., 2007; Zhang et al., 2009; Allen et al., 2013; Leibinger et al., 2013). Growth factors as promoters of regeneration are hobbled by two major issues. First, the signaling machinery that enables growth factors to drive axon growth in the developing nervous system is not expressed at sufficient levels in the adult nervous system (Hollis et al., 2009). Indeed, growth inhibitory signaling molecules such as the SOCS family or phosphatases are up-regulated upon maturation (Lu et al., 2002; Smith et al., 2009; Park et al., 2010; Gatto et al., 2013). Therefore, the most promising studies using growth factors have combined them with genetic intervention to up-regulate growth factor receptors or down-regulate their intrinsic inhibitors (Hollis et al., 2009; Sun et al., 2011). The second issue is that of undesirable side effects, especially that of neuropathic pain caused by neurotrophin administration (Obata et al., 2006; Jankowski and Koerber, 2009). Development of "painless" neurotrophins (Capsoni et al., 2011) may improve the usefulness of this family of growth factors in the context of regeneration. Future combined activation of several growth signaling pathways with blockade of growth inhibitory pathways may lead to realistic treatment options for patients with loss of vision, sensation, or locomotion.

\section{MATERIALS AND METHODS}

Mouse models. Mouse breeding and genotyping were performed as described previously (Mercer et al., 2005; Zhong et al., 2007). The animal protocol was approved by the Institutional Animal Care and Use Committee at Weill Cornell Medical College, and experiments were conducted in accordance with the National Institutes of Health Guide for the Use and Care of Laboratory Animals. The LSL-kaBraf mouse line was provided by C.A. Pritchard (University of Leicester, Leicester, England, UK; Mercer et al., 2005). The Trk $A^{\text {taulac } Z}$ mouse was provided by L. Reichardt (University of California, San Francisco, San Francisco, CA; Moqrich et al., 2004). Nestin-Cre deleter and Bax-null mice were generated in R. Klein's laboratory (Max Planck Institute of Neurobiology, Martinsried, Germany; Tronche et al., 1999) and S.J. Korsmeyer's laboratory (Dana-Farber Cancer Institute, Boston, MA; Knudson et al., 1995), respectively. The brn3a-CreER ${ }^{T 2}$ deleter mouse line was generated by J. Zhong in W.D. Snider's laboratory (University of North Carolina at Chapel Hill, Chapel Hill, NC). All mice were on a mixed 129Sv and C57BL/ 6 background. We used littermates as controls throughout.

Generation of the brn3a-CreER ${ }^{\mathrm{T} 2}$ deleter mouse line. Brn3a is a POU domain transcription factor that is selectively expressed in DRG neurons. Using a brn3a promoter construct (Eng et al., 2001), we generated a brn3a-Cre$E R^{T 2}$ deleter mouse line using the pronuclear injection technique (Fig. $6 \mathrm{~A}$ ).

Western blotting and immunohistochemical staining. Western blotting and immunohistochemical staining were performed as described previously (Zhong et al., 2007). An equal amount of total protein was loaded in each lane. The antibodies used were as follows: TrkA, Brn3a, and PlexinA1 antibodies were provided by L. Reichardt, E. Turner (University of California, San Diego, La Jolla, CA), and T. Jessell (Columbia University, New York, NY), respectively. Antibodies against MEK1/2 (9122), pMEK1/2 (9121), ERK1/2 (9102), pERK1/2 (9101), pAKT (9271 and 9275), phospho-p70S6K 
(9206), phospho-mTOR Ab (2971), and pGSK3ß (9336) were obtained from Cell Signaling Technology. $\beta$ III-Tubulin (AA10) was purchased from Invitrogen; Sema6D (S-16) was purchased from Santa Cruz Biotechnology, Inc.; C-RAF antibody (610151) was purchased from BD. Parvalbumin antibody (PV28) was obtained from Swant. CGRP antibodies (AB5920 and AB5705) were obtained from EMD Millipore. All Western blot and immunohistochemical experiments were repeated with tissue from at least three embryos for each genotype, and these embryos were obtained from a different litter for each experiment. Littermate controls were used throughout.

LacZ staining. E16.5 embryos were fixed in 4\% paraformaldehyde and stained with X-gal using EMD Millipore's Tissue Base staining solution according to the manufacturer's protocol. After imaging of axon skin innervation, embryos were dehydrated using a methanol in PBS dilution series $(25-50 \%$, $75-95 \%$, and $100 \%$ ), followed by incubation in $50 \%$ methanol: $50 \%$ benzoyl alcohol/benzoyl benzoate (BABB), and subsequently cleared in 100\% BABB (Sigma-Aldrich). Specimens were imaged with a M205A stereomicroscope equipped with a DFC310FX color digital camera system (Leica).

DRG culture. For CGRP expression assay, E12.5 DRGs derived from LSL-kaBraf:Bax ${ }^{-1-}$ :nes-Cre embryos were cultured with $100 \mathrm{ng} / \mathrm{ml} \mathrm{NGF}$ (Alomone Labs) and skin-conditioned medium for $8 \mathrm{~d}$. DRG neurons cultured in N2-supplied MEM (without NGF) were used as control. Both cultures where treated with FdU (5-fluoro-2-deoxyuridine; Sigma-Aldrich). Culture media were changed every $12 \mathrm{~h}$. The cells were fixed $8 \mathrm{~d}$ thereafter, and the cells were stained for CGRP and TrkA. For axon growth and neuron survival assays, DRGs were dissected from E12.5 embryos with the desired genotypes as described previously (Markus et al., 2002; Zhong et al., 2007). The cells were dissociated and plated on laminin-coated coverslips. Cells were then cultured in serum-free media supplemented with $1 \times \mathrm{N} 2$ (Invitrogen) and $1 \%$ BSA. FdU, NGF, or AAV2-Cre (Vector Laboratories) were added as described previously (Markus et al., 2002; Zhong et al., 2007).

Dorsal root crush. Surgeons and all other personnel performing experiments and analyses were blinded as to genotypes. 10-14-wk-old mice were injected s.c. with tamoxifen $(5 \mu \mathrm{g} / 10 \mathrm{~g}$ body weight) for a consecutive $5 \mathrm{~d}$. After another $2 \mathrm{~d}$, i.e., $1 \mathrm{wk}$ from the first tamoxifen injection, crush injury of the C5, C6, C7, and C8 dorsal roots was performed using a fine forceps (Dumont \#5) as described previously (Di Maio et al., 2011). AAV2-GFP ( $10^{10}$ GC, 7004; Vector Laboratories) was then injected to C6 and C7 DRGs. $2 \mathrm{wk}$ after the crush, mice were perfused, and axon regeneration through the C6 and C7 dorsal roots was analyzed in a thin dorsal slice preparation of whole spinal cord or in cryostat sections.

Sciatic nerve crush. Mice were injected with tamoxifen $(2 \mu \mathrm{g} / 10 \mathrm{~g}$ body weight) for a consecutive $5 \mathrm{~d}$, followed by $5 \mathrm{~d}$ of rest. Unilateral sciatic nerve crush was then performed as described previously (Zhong et al., 1999). Adult DRGs were collected and cultured as described previously (Zou et al., 2009). Images were taken using a Carl Zeiss LSM710NLO confocal microscope. Axon length was quantified as described previously (Zou et al., 2009).

Optic nerve crush. Surgeons and all other personnel performing experiments and analyses were blinded as to genotypes. The crush-regeneration and axon counting protocol is adapted from Park et al. (2008). Whole-mount optic nerves were treated with FocusClear (CelExplorer Labs) and scanned using an LSM710NLO multiphoton confocal microscope. OD was determined with the Carl Zeiss ZEN2009 software.

We would like to thank Louis Reichardt for the TrkAtulacz mice and TrkA antibody, Catrin A. Pritchard for the LSL-kaBraf mice, Eric Turner for the Brn3a promoter, and Thomas Jessell for the Plexin1A antibody. Larry Benowitz provided experimental advice on the optic nerve injury model. Rajiv Ratan, David Ginty, William D. Snider, and Annette Markus are acknowledged for insightful discussion and suggestions.

This work was supported by startup funds from the Burke Foundation as well as Whitehall Foundation research grant 2010-08-61, grants 1R01EY022409 and
3R01EY022409-01S1 from the National Eye Institute (NEI), and grant ZB1-1102-1 from the Christopher \& Dana Reeve Foundation to J. Zhong. Z. He is supported by grants 5R01EY21526 and EY021342 from NEI. Y.-J. Son is supported by grant 1R01NS079631 from the National Institute of Neurological Disorders and Stroke and grants from Shriners Hospitals for Children and the Muscular Dystrophy Association. H. Zou is supported by grants from the National Institutes of Health (1R01NS073596) and the Irma T. Hirschl/Monique Weill-Caulier Foundation. K.J. O'Donovan is a Goldsmith fellow.

The authors declare no competing financial interests.

Submitted: 24 August 2013

Accepted: 18 March 2014

\section{REFERENCES}

Agthong, S., J. Koonam, A. Kaewsema, and V. Chentanez. 2009. Inhibition of MAPK ERK impairs axonal regeneration without an effect on neuronal loss after nerve injury. Neurol. Res. 31:1068-1074. http://dx.doi.org/ 10.1179/174313209X380883

Allen, S.J., J.J. Watson, D.K. Shoemark, N.U. Barua, and N.K. Patel. 2013. GDNF, NGF and BDNF as therapeutic options for neurodegeneration. Pharmacol. Ther. 138:155-175. http://dx.doi.org/10.1016/j .pharmthera.2013.01.004

Benowitz, L.I., and Y. Yin. 2010. Optic nerve regeneration. Arch. Ophthalmol. 128:1059-1064. http://dx.doi.org/10.1001/archophthalmol.2010.152

Blackmore, M.G., Z. Wang, J.K. Lerch, D. Motti, Y.P. Zhang, C.B. Shields, J.K. Lee, J.L. Goldberg, V.P. Lemmon, and J.L. Bixby. 2012. Krüppellike Factor 7 engineered for transcriptional activation promotes axon regeneration in the adult corticospinal tract. Proc. Natl. Acad. Sci. USA. 109:7517-7522. http://dx.doi.org/10.1073/pnas.1120684109

Bonfiglio, J.J., G. Maccarrone, C. Rewerts, F. Holsboer, E. Arzt, C.W. Turck, and S. Silberstein. 2011. Characterization of the B-Raf interactome in mouse hippocampal neuronal cells. J. Proteomics. 74:186-198. http://dx.doi.org/10.1016/j.jprot.2010.10.006

Buchser, W.J., R.P. Smith, J.R. Pardinas, C.L. Haddox, T. Hutson, L. Moon, S.R. Hoffman, J.L. Bixby, and V.P. Lemmon. 2012. Peripheral nervous system genes expressed in central neurons induce growth on inhibitory substrates. PLoS ONE. 7:e38101. http://dx.doi.org/10.1371/ journal.pone. 0038101

Capsoni, S., S. Covaceuszach, S. Marinelli, M. Ceci, A. Bernardo, L. Minghetti, G. Ugolini, F. Pavone, and A. Cattaneo. 2011. Taking pain out of NGF: a "painless" NGF mutant, linked to hereditary sensory autonomic neuropathy type V, with full neurotrophic activity. PLoS ONE. 6:e17321. http://dx.doi.org/10.1371/journal.pone.0017321

Di Maio,A.,A. Skuba, B.T. Himes, S.L. Bhagat, J.K. Hyun,A.Tessler, D. Bishop, and Y.J. Son. 2011. In vivo imaging of dorsal root regeneration: rapid immobilization and presynaptic differentiation at the CNS/PNS border. J. Neurosci. 31:4569-4582. http://dx.doi.org/10.1523/JNEUROSCI .4638-10.2011

Eng, S.R., K. Gratwick, J.M. Rhee, N. Fedtsova, L. Gan, and E.E. Turner. 2001. Defects in sensory axon growth precede neuronal death in Brn3adeficient mice. J. Neurosci. 21:541-549.

Filbin, M.T. 2006. Recapitulate development to promote axonal regeneration: good or bad approach? Philos. Trans. R. Soc. Lond. B Biol. Sci. 361: 1565-1574. http://dx.doi.org/10.1098/rstb.2006.1885

Galabova-Kovacs, G., F. Catalanotti, D. Matzen, G.X. Reyes, J. Zezula, R. Herbst, A. Silva, I. Walter, and M. Baccarini. 2008. Essential role of B-Raf in oligodendrocyte maturation and myelination during postnatal central nervous system development. J. Cell Biol. 180:947-955. http://dx.doi .org $/ 10.1083 /$ jcb.200709069

Gatto, G., I. Dudanova, P. Suetterlin, A.M. Davies, U. Drescher, J.L. Bixby, and R. Klein. 2013. Protein tyrosine phosphatase receptor type O inhibits trigeminal axon growth and branching by repressing TrkB and Ret signaling.J. Neurosci. 33:5399-5410.http://dx.doi.org/10.1523/JNEUROSCI $.4707-12.2013$

Goldberg, J.L., J.S. Espinosa,Y. Xu, N. Davidson, G.T. Kovacs, and B.A. Barres. 2002. Retinal ganglion cells do not extend axons by default: promotion by neurotrophic signaling and electrical activity. Neuron. 33:689-702. http://dx.doi.org/10.1016/S0896-6273(02)00602-5 
Hall, A.K., X. Ai, G.E. Hickman, S.E. MacPhedran, C.O. Nduaguba, and C.P. Robertson. 1997. The generation of neuronal heterogeneity in a rat sensory ganglion. J. Neurosci. 17:2775-2784.

Hall, A.K., K.J. Dinsio, and J. Cappuzzello. 2001. Skin cell induction of calcitonin gene-related peptide in embryonic sensory neurons in vitro involves activin. Dev. Biol. 229:263-270. http://dx.doi.org/10.1006/dbio .2000 .9966

Han, S.B., H. Kim, A. Skuba, A. Tessler, T. Ferguson, and Y.J. Son. 2012. Sensory axon regeneration: A review from an in vivo imaging perspective. Exp. Neurobiol. 21:83-93. http://dx.doi.org/10.5607/en.2012.21.3.83

Hancock, M.L., D.W. Nowakowski, L.W.Role, D.A.Talmage, and J.G. Flanagan. 2011. Type III neuregulin 1 regulates pathfinding of sensory axons in the developing spinal cord and periphery. Development. 138:4887-4898. http://dx.doi.org/10.1242/dev.072306

Hanz, S., and M. Fainzilber. 2006. Retrograde signaling in injured nerve- the axon reaction revisited.J. Neurochem. 99:13-19. http://dx.doi.org/10.1111/ j.1471-4159.2006.04089.x

Harrison, S.M., B.M. Davis, M. Nishimura, K.M. Albers, M.E. Jones, and H.S Phillips. 2004. Rescue of NGF-deficient mice I: transgenic expression of NGF in skin rescues mice lacking endogenous NGF. Brain Res. Mol. Brain Res. 122:116-125. http://dx.doi.org/10.1016/j.molbrainres.2003 .12 .004

Harvey, P., B. Gong, A.J. Rossomando, and E. Frank. 2010. Topographically specific regeneration of sensory axons in the spinal cord. Proc. Natl. Acad. Sci. USA. 107:11585-11590. http://dx.doi.org/10.1073/pnas.1003287107

Hellal, F., A. Hurtado, J. Ruschel, K.C. Flynn, C.J. Laskowski, M. Umlauf, L.C. Kapitein, D. Strikis, V. Lemmon, J. Bixby, et al. 2011. Microtubule stabilization reduces scarring and causes axon regeneration after spinal cord injury. Science. 331:928-931. http://dx.doi.org/10.1126/science.1201148

Hollis, E.R. II, P. Jamshidi, K. Löw, A. Blesch, and M.H. Tuszynski. 2009. Induction of corticospinal regeneration by lentiviral trkB-induced Erk activation. Proc. Natl.Acad. Sci. USA. 106:7215-7220. http://dx.doi.org/ 10.1073/pnas.0810624106

Jankowski, M.P., and H.R. Koerber. 2009. Neurotrophic factors and nociceptor sensitization. In Translational Pain Research: From Mouse to Man. L. Kruger, and A.R. Light, editors. CRC Press, Boca Raton, FL. 31-50.

Knudson, C.M., K.S.Tung, W.G. Tourtellotte, G.A. Brown, and S.J. Korsmeyer. 1995. Bax-deficient mice with lymphoid hyperplasia and male germ cell death. Science. 270:96-99. http://dx.doi.org/10.1126/science.270 .5233 .96

Kuruvilla, R., L.S. Zweifel, N.O. Glebova, B.E. Lonze, G.Valdez,H.Ye, and D.D Ginty. 2004. A neurotrophin signaling cascade coordinates sympathetic neuron development through differential control of TrkA trafficking and retrograde signaling. Cell. 118:243-255. http://dx.doi.org/10.1016/j .cell.2004.06.021

Lang, C., P.M. Bradley, A. Jacobi, M. Kerschensteiner, and F.M. Bareyre. 2013. STAT3 promotes corticospinal remodelling and functional recovery after spinal cord injury. EMBO Rep. 14:931-937. http://dx.doi .org/10.1038/embor.2013.117

Leibinger, M., A. Müller, P. Gobrecht, H. Diekmann, A. Andreadaki, and D. Fischer. 2013. Interleukin-6 contributes to CNS axon regeneration upon inflammatory stimulation. Cell Death Dis. 4:e609. http://dx.doi .org/10.1038/cddis.2013.126

Lentz, S.I., C.M. Knudson, S.J. Korsmeyer, and W.D. Snider. 1999. Neurotrophins support the development of diverse sensory axon morphologies. J. Neurosci. 19:1038-1048.

Li, Y., C.L. Schlamp, K.P. Poulsen, and R.W. Nickells. 2000. Bax-dependent and independent pathways of retinal ganglion cell death induced by different damaging stimuli. Exp. Eye Res. 71:209-213. http://dx.doi.org/10 $.1006 /$ exer.2000.0873

Liu, K., Y. Lu, J.K. Lee, R. Samara, R. Willenberg, I. Sears-Kraxberger, A. Tedeschi, K.K. Park, D. Jin, B. Cai, et al. 2010. PTEN deletion enhances the regenerative ability of adult corticospinal neurons. Nat. Neurosci. 13: 1075-1081. http://dx.doi.org/10.1038/nn.2603

Lorber, B., M.L. Howe, L.I. Benowitz, and N. Irwin. 2009. Mst3b, an Ste20like kinase, regulates axon regeneration in mature CNS and PNS pathways. Nat. Neurosci. 12:1407-1414. http://dx.doi.org/10.1038/nn.2414

Lu, X., D. Maysinger, and T. Hagg. 2002. Tyrosine phosphatase inhibition enhances neurotrophin potency and rescues nigrostriatal neurons in adult rats. Exp. Neurol. 178:259-267. http://dx.doi.org/10.1006/exnr.2002 .8042

Luo, J.M., L.P. Cen, X.M. Zhang, S.W. Chiang, Y. Huang, D. Lin, Y.M. Fan, N. van Rooijen, D.S. Lam, C.P. Pang, and Q. Cui. 2007. PI3K/akt, JAK/ STAT and MEK/ERK pathway inhibition protects retinal ganglion cells via different mechanisms after optic nerve injury. Eur. J. Neurosci. 26:828842. http://dx.doi.org/10.1111/j.1460-9568.2007.05718.x

Lykissas, M.G., A.K. Batistatou, K.A. Charalabopoulos, and A.E. Beris. 2007. The role of neurotrophins in axonal growth, guidance, and regeneration. Curr. Neurovasc. Res. 4:143-151. http://dx.doi.org/10.2174/ 156720207780637216

Markus, A., J. Zhong, and W.D. Snider. 2002. Raf and akt mediate distinct aspects of sensory axon growth. Neuron. 35:65-76. http://dx.doi.org/10 .1016/S0896-6273(02)00752-3

Mercer, K., S. Giblett, S. Green, D. Lloyd, S. DaRocha Dias, M. Plumb, R. Marais, and C. Pritchard. 2005. Expression of endogenous oncogenic V600EB-raf induces proliferation and developmental defects in mice and transformation of primary fibroblasts. Cancer Res. 65:11493-11500. http://dx.doi.org/10.1158/0008-5472.CAN-05-2211

Moqrich, A., T.J. Earley, J. Watson, M. Andahazy, C. Backus, D. Martin-Zanca, D.E. Wright, L.F. Reichardt, and A. Patapoutian. 2004. Expressing TrkC from the TrkA locus causes a subset of dorsal root ganglia neurons to switch fate. Nat. Neurosci. 7:812-818. http://dx.doi.org/10.1038/nn1283

Müller, A., T.G. Hauk, M. Leibinger, R. Marienfeld, and D. Fischer. 2009. Exogenous CNTF stimulates axon regeneration of retinal ganglion cells partially via endogenous CNTF. Mol. Cell. Neurosci. 41:233-246. http:// dx.doi.org/10.1016/j.mcn.2009.03.002

Obata, K., H. Katsura, J. Sakurai, K. Kobayashi, H.Yamanaka,Y.Dai,T. Fukuoka, and K. Noguchi. 2006. Suppression of the p75 neurotrophin receptor in uninjured sensory neurons reduces neuropathic pain after nerve injury. J. Neurosci. 26:11974-11986. http://dx.doi.org/10.1523/JNEUROSCI $.3188-06.2006$

Parikh, P., Y. Hao, M. Hosseinkhani, S.B. Patil, G.W. Huntley, M. TessierLavigne, and H. Zou. 2011. Regeneration of axons in injured spinal cord by activation of bone morphogenetic protein/Smad1 signaling pathway in adult neurons. Proc. Natl. Acad. Sci. USA. 108:E99-E107. http://dx.doi .org/10.1073/pnas.1100426108

Park, K.K., K. Liu, Y. Hu, P.D. Smith, C. Wang, B. Cai, B. Xu, L. Connolly, I. Kramvis, M. Sahin, and Z. He. 2008. Promoting axon regeneration in the adult CNS by modulation of the PTEN/mTOR pathway. Science. 322:963-966. http://dx.doi.org/10.1126/science.1161566

Park, K.K., K. Liu, Y. Hu, J.L. Kanter, and Z. He. 2010. PTEN/mTOR and axon regeneration. Exp. Neurol. 223:45-50. http://dx.doi.org/10.1016/j .expneurol.2009.12.032

Patel,T.D., A. Jackman, F.L. Rice, J. Kucera, and W.D. Snider. 2000. Development of sensory neurons in the absence of NGF/TrkA signaling in vivo. Neuron. 25:345-357. http://dx.doi.org/10.1016/S0896-6273(00)80899-5

Pernet, V., W.W. Hauswirth, and A. Di Polo. 2005. Extracellular signal-regulated kinase 1/2 mediates survival, but not axon regeneration, of adult injured central nervous system neurons in vivo. J. Neurochem. 93:72-83. http:// dx.doi.org/10.1111/j.1471-4159.2005.03002.x

Pernet, V., S. Joly, N. Jordi, D. Dalkara, A. Guzik-Kornacka, J.G. Flannery, and M.E. Schwab. 2013. Misguidance and modulation of axonal regeneration by Stat3 and Rho/ROCK signaling in the transparent optic nerve. Cell Death Dis. 4:e734. http://dx.doi.org/10.1038/cddis.2013.266

Planchamp, V., C. Bermel, L. Tönges, T. Ostendorf, S. Kügler, J.C. Reed, P. Kermer, M. Bähr, and P. Lingor. 2008. BAG1 promotes axonal outgrowth and regeneration in vivo via Raf-1 and reduction of ROCK activity. Brain. 131:2606-2619. http://dx.doi.org/10.1093/brain/awn196

Ramer, M.S., J.V. Priestley, and S.B. McMahon. 2000. Functional regeneration of sensory axons into the adult spinal cord. Nature. 403:312-316. http://dx.doi.org/10.1038/35002084

Sapieha, P.S., W.W. Hauswirth, and A. Di Polo. 2006. Extracellular signalregulated kinases $1 / 2$ are required for adult retinal ganglion cell axon regeneration induced by fibroblast growth factor-2. J. Neurosci. Res. 83: 985-995. http://dx.doi.org/10.1002/jnr.20803

Seijffers, R.,C.D.Mills, and C.J.Woolf. 2007.ATF3 increases the intrinsic growth state of DRG neurons to enhance peripheral nerve regeneration. J. Neurosci. 27:7911-7920. http://dx.doi.org/10.1523/JNEUROSCI.5313-06.2007 
Shin, J.E.,Y. Cho, B. Beirowski, J. Milbrandt,V. Cavalli, and A. DiAntonio. 2012 Dual leucine zipper kinase is required for retrograde injury signaling and axonal regeneration. Neuron. 74:1015-1022. http://dx.doi.org/10.1016/ j.neuron.2012.04.028

Smith, D.S., and J.H. Skene. 1997. A transcription-dependent switch controls competence of adult neurons for distinct modes of axon growth. $J$. Neurosci. 17:646-658.

Smith, G.M., A.E. Falone, and E. Frank. 2012. Sensory axon regeneration: rebuilding functional connections in the spinal cord. Trends Neurosi. 35: 156-163. http://dx.doi.org/10.1016/j.tins.2011.10.006

Smith, P.D., F. Sun, K.K. Park, B. Cai, C. Wang, K. Kuwako, I. MartinezCarrasco, L. Connolly, and Z. He. 2009. SOCS3 deletion promotes optic nerve regeneration in vivo. Neuron. 64:617-623. http://dx.doi .org/10.1016/j.neuron.2009.11.021

Sun, F., K.K. Park, S. Belin, D. Wang, T. Lu, G. Chen, K. Zhang, C. Yeung, G. Feng, B.A. Yankner, and Z. He. 2011. Sustained axon regeneration induced by co-deletion of PTEN and SOCS3. Nature. 480:372-375 http://dx.doi.org/10.1038/nature10594

Tronche, F, C. Kellendonk, O. Kretz, P. Gass, K. Anlag, P.C. Orban, R. Bock, R. Klein, and G. Schütz. 1999. Disruption of the glucocorticoid receptor gene in the nervous system results in reduced anxiety. Nat. Genet. 23:99-103. http://dx.doi.org/10.1038/12703

Wang, R., T. King, M.H. Ossipov, A.J. Rossomando, T.W.Vanderah, P. Harvey, P. Cariani, E. Frank, D.W. Sah, and F. Porreca. 2008. Persistent restoration of sensory function by immediate or delayed systemic artemin after dorsal root injury. Nat. Neurosci. 11:488-496. http://dx.doi.org/10.1038/ nn2069

Williams, K.A., M. Zhang, S. Xiang, C. Hu, J.Y.Wu, S. Zhang, M. Ryan, A.D. Cox, C.J. Der, B. Fang, et al. 2013. Extracellular signal-regulated kinase
(ERK) phosphorylates histone deacetylase 6 (HDAC6) at serine 1035 to stimulate cell migration. J. Biol. Chem. 288:33156-33170. http://dx.doi .org/10.1074/jbc.M113.472506

Xu, P., and A.K. Hall. 2007. Activin acts with nerve growth factor to regulate calcitonin gene-related peptide mRNA in sensory neurons. Neuroscience. 150:665-674. http://dx.doi.org/10.1016/j.neuroscience.2007.09.041

Yan, D., Z. Wu, A.D. Chisholm, and Y. Jin. 2009. The DLK-1 kinase promotes mRNA stability and local translation in C. elegans synapses and axon regeneration. Cell. 138:1005-1018. http://dx.doi.org/10.1016/J cell.2009.06.023

Yoshida,Y., B. Han, M. Mendelsohn, and T.M. Jessell. 2006. PlexinA1 signaling directs the segregation of proprioceptive sensory axons in the developing spinal cord. Neuron. 52:775-788. http://dx.doi.org/10.1016/j .neuron.2006.10.032

Zhang, L., Z. Ma, G.M. Smith, X. Wen, Y. Pressman, P.M. Wood, and X.M Xu. 2009. GDNF-enhanced axonal regeneration and myelination following spinal cord injury is mediated by primary effects on neurons. Glia. 57:1178-1191. http://dx.doi.org/10.1002/glia.20840

Zhong, J., I.D. Dietzel, P. Wahle, M. Kopf, and R. Heumann. 1999. Sensory impairments and delayed regeneration of sensory axons in interleukin6-deficient mice. J. Neurosci. 19:4305-4313.

Zhong,J., X. Li, C. McNamee,A.P. Chen, M. Baccarini, and W.D. Snider. 2007. Raf kinase signaling functions in sensory neuron differentiation and axon growth in vivo. Nat. Neurosci. 10:598-607. http://dx.doi.org/10.1038/ nn1898

Zou, H., C. Ho, K. Wong, and M. Tessier-Lavigne. 2009. Axotomy-induced Smad1 activation promotes axonal growth in adult sensory neurons. J. Neurosci. 29:7116-7123. http://dx.doi.org/10.1523/JNEUROSCI $.5397-08.2009$ 